\title{
Complutum
}

ISSN: 1131-6993

\section{Cuevas rituales ibéricas en el territorio de Kelin (ss. V-III a.C.)}

\author{
Sonia Machause López ${ }^{1}$; David Quixal Santos ${ }^{2}$ \\ Aceptado: 02 de enero de 2017 / Aceptado: 19 de noviembre de 2018.
}

Resumen. La Meseta de Requena-Utiel, en el interior de la provincia de Valencia, constituyó en época ibérica el territorio de la ciudad de Kelin. Entre otros aspectos, dicho territorio destacó por presentar una elevada concentración de cuevas con materiales ibéricos, de las cuales claramente cinco son resultado de prácticas rituales en su interior. Estas cuevas rituales fueron espacios estrechamente ligados al proceso de territorialización acaecido en la zona entre los siglos V y III a.C. En el presente artículo planteamos una revisión de sus características, ajuares y cronologías, integrándolas en todo momento en el paisaje y entorno inmediato.

Palabras clave: Cuevas rituales; cuevas-santuario, Edad del Hierro, Arqueología del Paisaje, territorialidad ibérica.

\section{[en] Iberian ritual caves in the territory of Kelin (V-III bc)}

Abstract. The Requena-Utiel plateau, in the interior of the Province of Valencia, was within the territory of the city of Kelin during the Iberian Iron Age. One significant aspect of this territory is a high concentration of caves with Iberian materials. Cultural deposits in five of these caves are clearly the result of ritual practices inside. These ritual caves were spaces closely linked to the process of territorialization which occurred in the area between the 5th and 3rd centuries BC. In this article we reexamine those features, materials and associated chronologies, always integrating them with the nearby landscape and surroundings.

Key words: Ritual caves; sanctuary-caves; Iron Age; Landscape Archaeology; Iberian territoriality.

Sumario: 1. La investigación de las "cuevas-santuario" en el mundo ibérico. 2. La Meseta de Requena-Utiel: El territorio de la ciudad ibérica de Kelin. 3. Catálogo de cuevas con materiales ibéricos. 4. Las cuevas como elementos integrados en el territorio. 5. Comunidades, rituales y territorialidad. Conclusiones.

Cómo citar: Machause López, S.; Quixal Santos, D. (2018): Cuevas rituales ibéricas en el territorio de Kelin (ss. V-III a.C.). Complutum, 29(1): 115-134.

\section{La investigación de las "cuevas-santuario" en el mundo ibérico}

El término de "cueva-santuario" asociado a materiales ibéricos tiene su origen en el ámbito valenciano, cuando se documentaron cerámicas de esta cronología en una cueva de Sella (Alicante) (Gómez Serrano 1931: 79). Sin embargo, a principios del s. XX prevalecía la visión de las cuevas como simples espacios de hábitat en época ibérica (Tarradell 1973), si bien es cierto que muchos de los hallazgos de esta cronología procedían de prospecciones o excavaciones centradas en ocupaciones prehistóricas. Durante la primera mitad del s. XX se citaba la presencia de materiales ibéricos en cuevas (Pericot 1946), pero todavía no se profundizaba en su interpretación. La presencia de elementos claramente de carácter cultual, como los exvotos de terracota de la Cova de les Meravelles (Gandia, Valencia), se asociaron con un uso funerario ( $\mathrm{Pla}$ Ballester 1945); del mismo modo que los materiales ibéricos hallados en la Cova dels Sants (L'Alcudia de Crespins, Valencia) despertaron el interés por las ofrendas que se realizarían en estas cavidades (Pla Ballester 1966: 295).

\footnotetext{
Departament de Prehistòria, Arqueologia i Història Antiga. Grup de Recerca en Arqueologia del Mediterrani (GRAM). Universitat de València. Av. Blasco Ibáñez, 2846010 València Sonia.machause@uv.es

2 Departament de Prehistòria, Arqueologia i Història Antiga. Grup de Recerca en Arqueologia del Mediterrani (GRAM). Universitat de València. Av. Blasco Ibáñez, 2846010 València David.quixal@uv.es
} 
Fue en los años 70 cuando M. Gil-Mascare11 (1975) y M. Tarradell (1973) remarcaron el vacío existente en los estudios sobre este tema. El trabajo de M. Gil-Mascarell dio paso a una nueva etapa en la investigación, estableciendo unos rasgos comunes que definían a las cuevas como lugares de culto. Se diferenciaron, por primera vez, las "cuevas-refugio" de las "cuevas-santuario o rituales" y se señalaron los vasos caliciformes como uno de los materiales más significativos de estas últimas, así como su relación con el agua y sus complicados accesos. Además, se planteó también la conexión que pudieron tener con los núcleos cercanos, proponiendo una vinculación territorial (Gil-Mascarell 1975). Esta investigación supuso una obra de referencia en los estudios sobre ritualidad, del mismo modo que el catálogo espeleológico de J. Donat (1966), continuado y completado por J. Fernández et al. (1982), se convirtieron en obras de referencia para conocer las características físicas y geológicas de las cavidades valencianas.

Tras la obra de M. Gil-Mascarell, podemos diferenciar, a grandes rasgos, dos momentos en la investigación sobre la ritualidad ibérica en cuevas. Una primera etapa entre 1975 y 2000/2005, aproximadamente, cuando se realizaron las primeras excavaciones arqueológicas con el objetivo de obtener nuevas informaciones sobre su uso en época ibérica, como es el caso de la Cueva del Puntal del Horno Ciego II (Villargordo del Cabriel, Valencia) (Gil-Mascarell 1977; Martí-Bonafé 1990) o la Cueva Merinel (Bugarra, Valencia) (Aparicio et al. 1983: 375-385; Blay 1992; Martínez Perona 1992). También comenzaron los estudios exhaustivos de materiales ibéricos, como las citadas con anterioridad u otras como la Cova dels Pilars (Agres, Alicante) (Grau 1996), la Cova de la Moneda (Ibi, Alicante) (Cerdà 1996), la Cova de les Encantades del Montcabrer (Cabrera de Mar, Barcelona) (Coll et al. 1994), las cuevas de Cerro Hueco y los Ángeles (Requena, Valencia) (Martínez Valle y Castellano 1996); y se multiplicaron los catálogos de cuevas con materiales ibéricos en el área valenciana (Aparicio 1976; Serrano y Fernández 1992; González-Alcalde 1993, 2002-2003a y b), catalana (Vega 1987; Ros 2003) y murciana (González-Alcalde 2005), incluyéndose además en las categorizaciones sobre lugares de culto (Lucas 1981; Prados 1994; Bonet y Mata 1997; Domínguez Monedero 1997; Moneo 2003, entre otros). Estos estudios supusieron un gran avance para el co- nocimiento básico sobre dónde se situaban las cuevas, cuáles eran los materiales comúnmente asociados con estos espacios y qué actividades se llevaban a cabo allí.

Sin embargo, a partir de 2000/2005 comienzan a proponerse nuevas líneas de investigación que no buscan establecer los rasgos comunes a toda el área ibérica, sino que se centran en casos concretos, para demostrar la diversidad existente en el ámbito de la ritualidad. A su vez, se aplican los recursos que las nuevas tecnologías ofrecen, en especial los derivados de los Sistemas de Información Geográfica (SIG) (Grau 2002; Grau y Olmos 2005; Grau y Amorós 2013).

Por suerte, a día de hoy nos encontramos en un momento álgido de la investigación sobre este tipo de contextos (Amorós 2012; Machause et al. 2014; López-Mondéjar 2015; Rísquez y Rueda 2013; Ocharán 2015; López-Bertran 2015, entre otros), con un creciente interés por obtener nuevos datos a través de prospecciones y excavaciones con metodología actual (Ocharán 2014, Rueda c.o.). Además, estos espacios han superado el marco de la ritualidad y poco a poco se están teniendo en cuenta a la hora de analizar algunos territorios ibéricos (Canela 2014; Quixal 2015). Siguiendo esta línea, proponemos una lectura interpretativa y territorial de las cuevas rituales en el territorio ibérico de Kelin ${ }^{1}$.

\section{La Meseta de Requena-Utiel: El territorio de la ciudad ibérica de Kelin}

La Meseta de Requena-Utiel constituye una unidad geográfica bien diferenciada, de transición entre el litoral valenciano y la meseta castellana (Piqueras 1997). Se trata de una de las comarcas españolas de mayor extensión, que ocupa buena parte del sector occidental de la provincia de Valencia (fig. 1). Destaca por una alta heterogeneidad geográfica, con zonas con características, relieve y vegetación muy diversas; un contraste que se ha visto directamente relacionado con el patrón de asentamiento pretérito (Quixal 2015: 30-32). El espacio central está plagado de llanos y lomas en los que se desarrollan cultivos de secano, mientras que las zonas limítrofes presentan relieves más irregulares, con sierras (Martés, Cabrillas, Tejo o Juan Navarro) y depresiones creadas por profundos cursos fluviales $(\mathrm{Ca}-$ briel y Magro). 


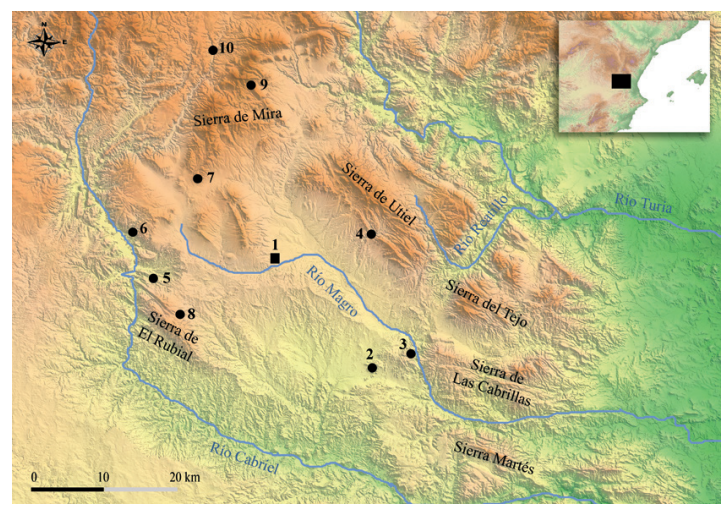

Figura 1. Mapa general del área de estudio, con los principales yacimientos citados: 1 . Kelin; 2. Cerro Hueco; 3. Cueva de los Ángeles; 4. Cueva de los Mancebones; 5. Cueva del Puntal del Horno Ciego II; 6. Cueva Santa del Cabriel; 7. Cueva de El Molón; 8. Cueva Santa de Villargordo; 9. Cueva del Collado de la Plata; 10. Cueva de la Tejeda.

Desde hace más de dos décadas, se ha defendido que esta comarca se corresponde, aproximadamente, con lo que en época ibérica constituiría el territorio de la ciudad de Kelin/ Los Villares (Caudete de las Fuentes, Valencia) (Mata et al. 2001; Moreno 2011; Quixal 2015). Las excavaciones en este yacimiento desde mediados del siglo pasado han sacado a la luz restos e información de un oppidum de unas 10 ha, con toda una serie de elementos que permiten abogar su estatus de lugar central (concentración de bienes de prestigio, urbanismo desarrollado, acuñación de moneda, muestras de escritura, etc.) (Mata 1991). Y, de forma paralela a las excavaciones, las campañas de prospección desarrolladas desde los años 90, han permitido conocer un denso y jerarquizado poblamiento, con más de 200 yacimientos de entre los ss. VII-I a.C.

Dentro de esta línea de investigación, ha imperado siempre el análisis del poblamiento y hábitat rural (Mata et al. 2009; Quixal et al. 2010), así como el estudio de la producción de vino en la antigüedad (Quixal et al. 2016), a partir de las múltiples excavaciones y prospecciones llevadas a cabo en el municipio de Requena. En cambio, las esferas sacra y funeraria siempre han quedado relegadas a un segundo plano, algo que pretendemos paliar con este y futuros trabajos.

Pese a la gran extensión de esta área, a nivel geológico no podemos decir que sea especialmente rica en cuevas. Las hay, sobre todo con- centradas en zonas limítrofes y serranas, pero no en una abundancia y singularidad semejante a otras comarcas cercanas como Los Serranos o el Valle de Cofrentes-Ayora. Por lo general, lo que hay son covachas de reducidas dimensiones, con una o dos salas pequeñas y los habituales espacios secundarios, sin formaciones kársticas especialmente complejas. Este hecho enlaza con la escasez de yacimientos prehistóricos en cueva, a excepción de los ejemplos documentados de cuevas sepulcrales del Calcolítico y/o la Edad del Bronce (VVAA 1976: 28-29; Molina y Pedraz 2000). Por ello otorgamos una mayor singularidad a la abundancia de cuevas con uso en época ibérica y a las prácticas rituales que se pudieron desarrollar en ellas.

\section{Catálogo de cuevas con materiales ibéricos}

En el territorio de Kelin conocemos nueve cuevas con materiales que demuestran frecuentación en época ibérica (fig. 1). Sin embargo, en este artículo nos centraremos en los cinco ejemplos que, a día de hoy, presentan serias evidencias de una actividad ritual: $\mathrm{Ce}-$ rro Hueco, Cueva de los Ángeles y Cueva de los Mancebones en Requena; Puntal del Horno Ciego II en Villargordo del Cabriel y la Cueva Santa del Cabriel en Mira (fig. 2). Otras cavidades cuyas evidencias son dudosas o poco significativas, cuantitativa y cualitativamente, serán tratadas de forma secundaria. Este es el caso de la Cueva de El Molón (Camporrobles, Valencia), la Cueva Santa (Villargordo del Cabriel, Valencia), la Cueva del Collado de la Plata (Aliaguilla, Cuenca) y la Cueva de la Tejeda (Garaballa, Cuenca).

\section{Cuevas con evidencias de actividad ritual}

De las cinco cuevas incluidas en este estudio, tan solo una ha sido objeto de una excavación arqueológica: el Puntal del Horno Ciego II (Gil-Mascarell 1977). La frecuentación ibérica en el resto se ha documentado mediante prospecciones arqueológicas, así como a partir de hallazgos casuales y/o rebuscas clandestinas, algunas de los cuales han nutrido los museos y colecciones museográficas locales (Aparicio y Latorre 1977). Presentaremos de forma general las características de cada uno, así como los resultados preliminares obtenidos a través de la revisión de los materiales, en aquellos casos en los que ha sido posible (figs. 2-6). 


\begin{tabular}{|c|c|c|c|c|c|c|c|c|c|c|}
\hline $\mathbf{N}^{\mathbf{0}}$ & Nombre & msnm & $\begin{array}{l}\text { Orientación } \\
\text { boca }\end{array}$ & Cronología & $\begin{array}{l}\text { Objeto más } \\
\text { repetido }\end{array}$ & Otros elementos & $\begin{array}{c}\text { Restos } \\
\text { humanos }\end{array}$ & $\begin{array}{c}\text { Restos de } \\
\text { fauna }\end{array}$ & $\begin{array}{l}\text { Frecuentación } \\
\text { anterior }\end{array}$ & $\begin{array}{l}\text { Frecuentación } \\
\text { posterior }\end{array}$ \\
\hline 1 & $\begin{array}{l}\text { Cerro Hueco } \\
\text { (Requena) }\end{array}$ & 620 & Sima & V-III a.C. & Fusayolas & $\begin{array}{l}\text { Imporataciones, una de ellas } \\
\text { decorada }\end{array}$ & Sí & Sí & No & Sí \\
\hline 2 & $\begin{array}{l}\text { Cueva de los Ángeles } \\
\text { (Requena) }\end{array}$ & 759 & $S$ & V-III a.C. & Fusayolas & Importaciones & No & Sí & No & No \\
\hline 3 & $\begin{array}{l}\text { Cueva de los Mancebones } \\
\text { (Requena) }\end{array}$ & 889 & NW & V-III a.C. & $\begin{array}{l}\text { Fusayolas y } \\
\text { caliciformes }\end{array}$ & Importaciones y miniaturas & Sí & No & Sí & No \\
\hline 4 & $\begin{array}{l}\text { Puntal del Horno Ciego II } \\
\text { (Villargordo del Cabriel) }\end{array}$ & 780 & Sima & V-III a.C. & Caliciformes & $\begin{array}{c}\text { Anillos (decoración figurada) } \\
\text { y miniaturas }\end{array}$ & Sí & Sí & Sí & No \\
\hline 5 & $\begin{array}{l}\text { Cueva Santa del Cabriel } \\
\text { (Mira) }\end{array}$ & 860 & NW & V-III a.C. & $\begin{array}{l}\text { Caliciformes y } \\
\text { platos }\end{array}$ & $\begin{array}{l}\text { Importaciones y mano de } \\
\text { mortero figurada en miniatura }\end{array}$ & Sí & Sí & Sí & Sí \\
\hline
\end{tabular}

Figura 2. Datos significativos de las cuevas rituales del territorio de Kelin.

La cueva del Cerro Hueco se localiza en la ladera Sur de un pequeño cerro con el mismo nombre, cercano a la aldea requenense de Campo Arcís. Situada a $620 \mathrm{msnm}$, su acceso no es visible desde el llano, ya que se trata de una boca circular de $1 \mathrm{~m}$ de diámetro de tipo sima (fig. 3.1). Es una cavidad de reducidas dimensiones que fue visitada por última vez en 2004, antes de que un desprendimiento bloquease prácticamente la entrada. La galería de acceso original tenía una longitud de $10 \mathrm{~m}$, dando paso a dos salas, una principal $(15 \times 10 \times 2,5 \mathrm{~m})$ y otra secundaria $(5 \times 5 \times 2 \mathrm{~m})$ (Fernández et al. 1982: 144-145). Los materiales ibéricos recogidos por el Grupo Arqueológico Requenense y J. Aparicio fueron depositados para su estudio en el Museu de Prehistòria de València (MPV), siendo posteriormente trasladados en 1973 al Museo Municipal de Requena (VVAA 1974: 96, 1975: 115; Aparicio 1976: 15) (fig. 6.7). Lamentablemente, en dicho traslado se mezclaron con los recogidos en la Cueva de los Ángeles (Martínez Valle y Castellano 1996). Sin embargo, a través de las informaciones reflejadas en el Archivo Fotográfico del SIP, hemos logrado identificar algunas de estas piezas. Destacan en número las fusayolas: 36 fotografiadas, aunque pudieron recogerse en esta cueva hasta 200 ejemplares (fig. 4.9) (Martínez Valle y Castellano 1996). También se documentaron caliciformes y platos, así como dos bases de formas abiertas de cerámica ática recortadas (fig. 4.4), dos páteras L24 y L24/25 y cuatro anillos de bronce decorados (fig. 4.5), aunque su conservación dificulta identificar los motivos decorativos. Entre el conjunto de materiales es interesante indicar la presencia de varios fragmentos de Terra Sigillata Hispánica (Gil-Mascarell 1975: 307), cuya presencia anecdótica no parece evidenciar una práctica ritual en época imperial (Quixal 2015: 45). Además, también se cita la presencia de restos de fauna y restos humanos (Aparicio y Latorre 1977). A este registro material, únicamente podemos añadir tres bordes de caliciformes en superficie hallados en nuestras prospecciones (Quixal 2008: fig. 187) (fig. 5). La cronología que aportan las cerámicas de importación, así como algunas cerámicas ibéricas con decoración bícroma (Bonet y Mata 1997), se enmarcaría entre los ss. V-IV a.C.

La Cueva de los Ángeles se encuentra en plena sierra de Las Cabrillas, a 759 msnm, entre el barranco de Las Zorreras y la Casa del Cura, en la vertiente derecha del barranco de Los Conejos, afluente del río Magro (Fernández et al. 1982: 143; Martínez y Castellano 1996: 525). Se trata de una pequeña cueva de difícil acceso, cuya entrada fue ensanchada por los cazadores que la descubrieron en los años 40 (Aparicio 1976). Actualmente, el acceso tiene una altura máxima de $0,70 \mathrm{~m}$ y una anchura máxima de $1,5 \mathrm{~m}$ (fig. 3.5). Cuenta con una galería de acceso de unos $3 \mathrm{~m}$ por la que hay que serpentear para acceder a la cueva. Las formaciones kársticas que plagan su interior la dividen en 4 espacios: el pasillo y vestíbulo de acceso y tres salas de entre 8 y $15 \mathrm{~m}$ de profundidad cada una al Noroeste, Este y Oeste del acceso ${ }^{2}$. Parece ser que sus descubridores encontraron in situ bastantes vasos cerámicos en las oquedades de las paredes, del mismo modo que J. Aparicio y otros miembros del SIP pudieron recuperar en superficie fragmentos de los mismos durante su visita (Aparicio 1976: 15) (fig. 6.2 y 6.3). Tal y como hemos comentado con anterioridad, los materiales de esta cueva se mezclaron con los de Cerro Hueco cuando fueron trasladados del SIP al Museo Municipal de Requena (VVAA 1975: 115). De hecho, en la bibliografía existe una constante repetición a la hora de referirse a las mismas piezas para ambas cuevas. Si nos basamos en 
las descripciones de la Labor del SIP, parece que al menos las cerámicas de importación y la mayoría de fusayolas provendrían de Cerro Hueco (VVAA 1974: 96), mientras que tan solo 10 fusayolas y algunos vasos caliciformes, provendrían de la Cueva de los Ángeles (Aparicio y Latorre 1977: 31; Martínez Valle y Castellano 1996: 525) (fig. 5). Por último, es interesante indicar la presencia de un número elevado de restos de fauna (Aparicio 1976: 15; Aparicio y Latorre 1977: 32). Al no haber tenido acceso a los materiales, somos incapaces de realizar apreciaciones cronológicas dentro de un amplio periodo entre los ss. V-III a.C.
La Cueva de los Mancebones, también conocida como del Santo Estoleto, Estalote o Amancebados, está situada a $889 \mathrm{msnm}$, en plena rambla de Estenas (Donat 1966: 122; Fernández et al. 1982: 149). Del mismo modo, consideramos que se trata también de la Cueva del Requejo citada por M. Gil-Mascarell (1975: 289), dado que dicho es el topónimo del paraje donde se ubica. La boca de la cavidad, orientada hacia el Noroeste, tiene una apertura máxima de $2 \times 1 \mathrm{~m}$ (fig. 3.2). A través de ésta se accede a un pequeño vestíbulo y un pasillo de unos $10 \mathrm{~m}$, que finaliza en una sala de $4 \times 3 \mathrm{~m}$. Fue en esta última donde se recogieron los ma-
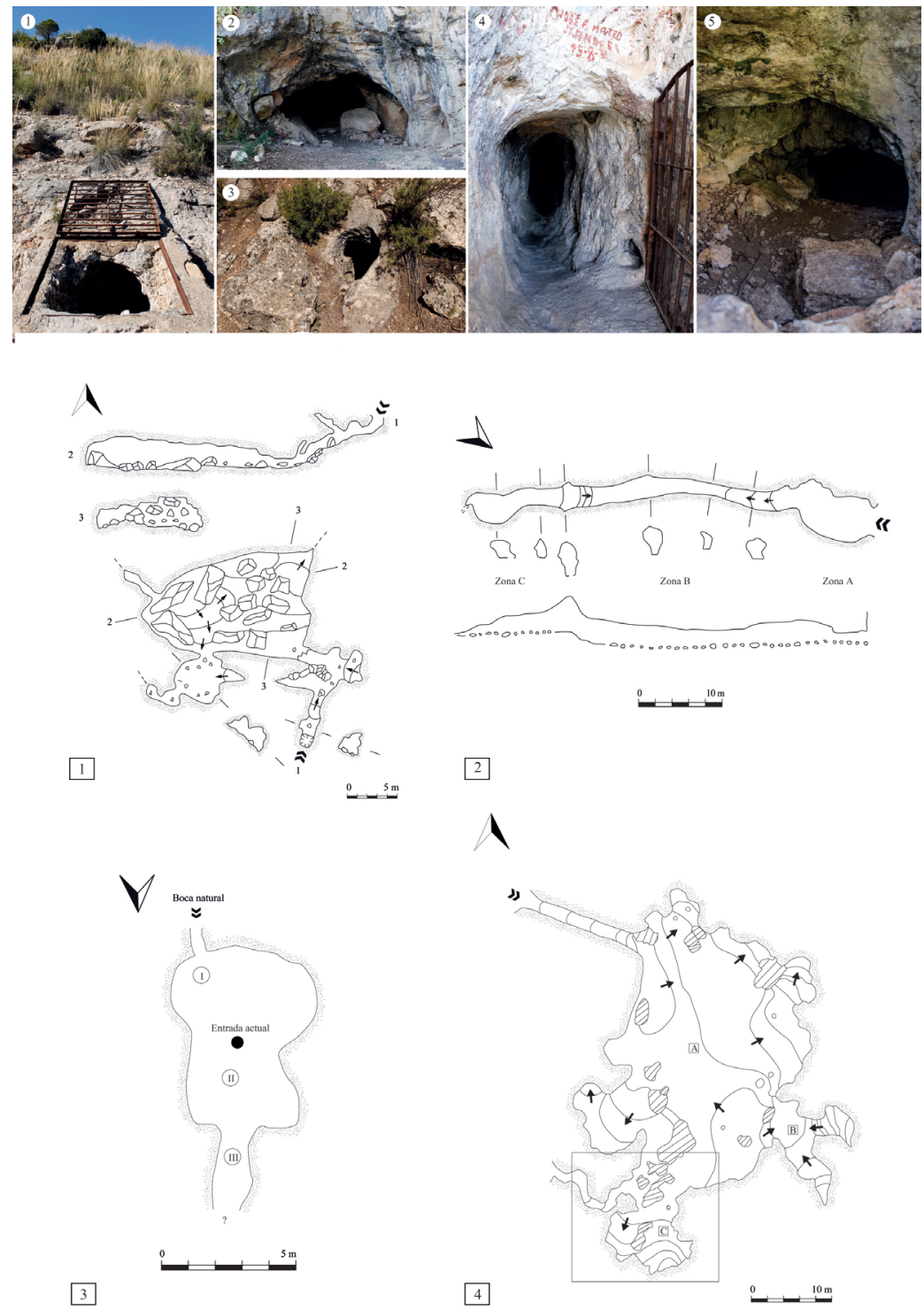

Figura 3. Bocas y planos de las cuevas rituales ibéricas (fotografías de los autores): 1. Cerro Hueco (a partir Fernández et al. 1982: 144); 2. Cueva de los Mancebones (a partir Fernández et al. 1982: 149); 3. Puntal del Horno Ciego II (a partir Lorrio et al. 2002); 4. Cueva Santa del Cabriel (a partir Lorrio et al. 2006: fig. 2, con referencia a la zona prospectada en 2003); 5. Cueva de los Ángeles. 
teriales ibéricos (Gil-Mascarell 1975: 305); de hecho, en nuestra visita de 2016 todavía observamos material en superficie, principalmente fragmentos de vasos caliciformes y restos de fauna. Aunque su existencia se conoce desde finales del s. XIX, no ha sido objeto de ninguna excavación arqueológica. La mayoría de sus materiales fueron recopilados por J. M. Martínez García y se encuentran en la Colección Museográfica de Utiel, de reciente creación, aunque el MPV conserva algunos fragmentos procedentes de una prospección anterior. Estos últimos son, en su totalidad, cerámicas (tres bases de caliciformes) (fig. 5). Además, M. Gil-Mascarell cita una "gran cantidad de vasos caliciformes de cocción reductora", así como fusayolas con decoración a base de incisiones (1975: 305-306). Del mismo modo, contamos con una referencia de cerámicas grises monócromas sin procedencia clara, recogida en una publicación de C. Aranegui (1975: 359), y un adorno realizado sobre pecten (González-Alcalde 2002-2003a: 203). Destacamos, además, la existencia de exvotos de terracota, elementos poco comunes en las cuevas de esta zona, y fusayolas (algunas de ellas miniaturizadas) conservados en la colección de Utiel (fig. 4.3). Finalmente, es interesante indicar la presencia de restos humanos (Gil-Mascarell 1975: 306), que pudieron estar relacionados tanto con momentos previos, incrementando el valor ritual del espacio, como con los materiales de época ibérica, tal y como hemos documentado recientemente en otras cuevas (Machause et al. 2014). En cuanto a datación, tan sólo una pátera ática de la forma L24, conservada en Utiel, nos sitúa en torno al s. IV a.C. El resto de los materiales, sin embargo, no nos permiten especificar un momento concreto dentro de los ss. V-III a.C.

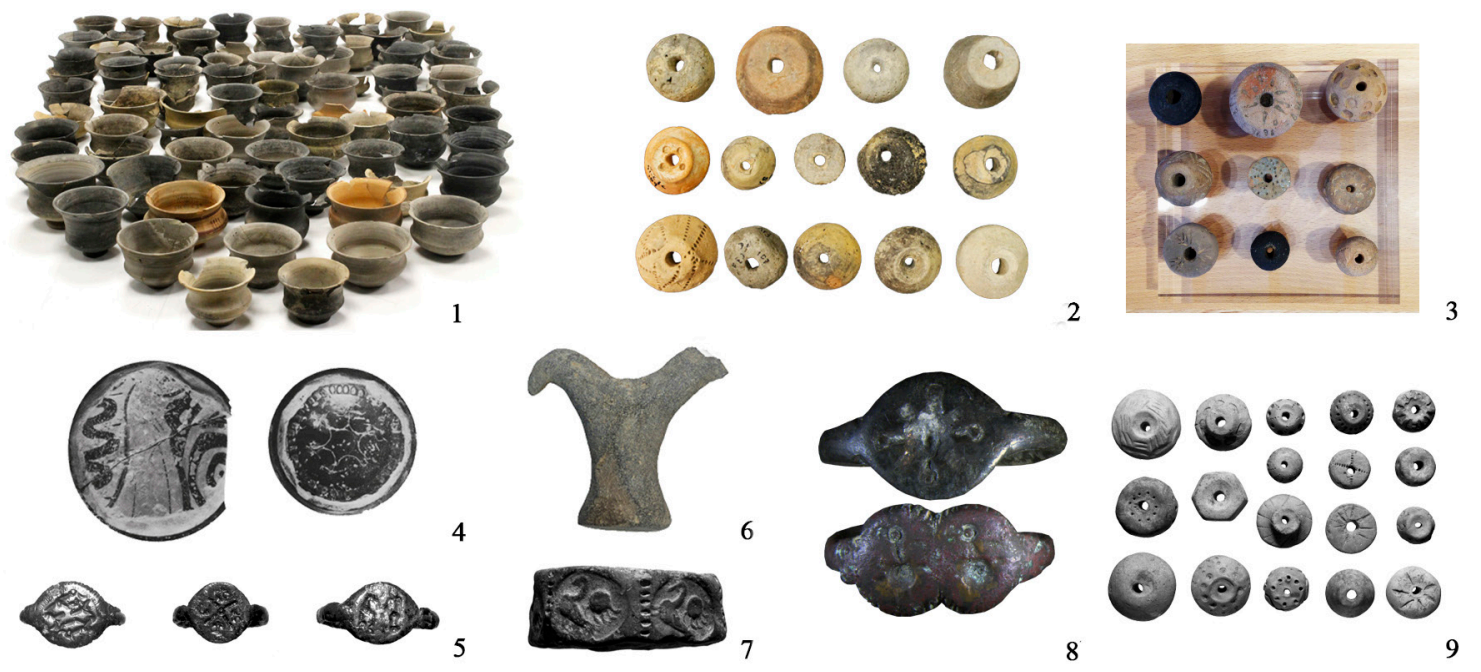

Figura 4. Materiales arqueológicos más representativos: 1, 2 y 8. Puntal del Horno Ciego II (fotografías de los autores); 3. Cueva de los Mancebones (Colección Museográfica de Utiel); 4, 5, 7 y 9. Cerro Hueco (Archivo Fotográfico del SIP); 6. Cueva Santa del Cabriel (fotografía de los autores). Diferentes escalas.

La cueva del Puntal del Horno Ciego II está situada a $780 \mathrm{msnm}$ en la partida del mismo nombre. Se localiza en una zona kárstica plagada de cavidades, en una ladera de los Montes de Peñablanca. El acceso actual -y también en época ibérica- se realiza por una apertura circular de $0,5 \mathrm{~m}$ de diámetro, situada en la bóveda de la cavidad a $4 \mathrm{~m}$ del suelo (VVAA 1976: 115; Gil-Mascarell 1977: 706; Fernández et al. 1982: 157-158; Martí Bona- fé 1990: 144) (fig. 3.3). En el interior, aparte de la sala principal, se abren varias galerías y grietas tanto hacia el Norte como hacia al Sur, siendo una de ellas el acceso natural de la cavidad, por donde entra actualmente la luz. $\mathrm{Su}$ hallazgo, así como el de la cueva I, se produjo por vecinos de Villargordo del Cabriel, quienes en agosto de 1974 informaron al SIP de la recogida de varios vasos ibéricos completos (VVAA 1976: 115). Cuando M. Gil-Mascarell 

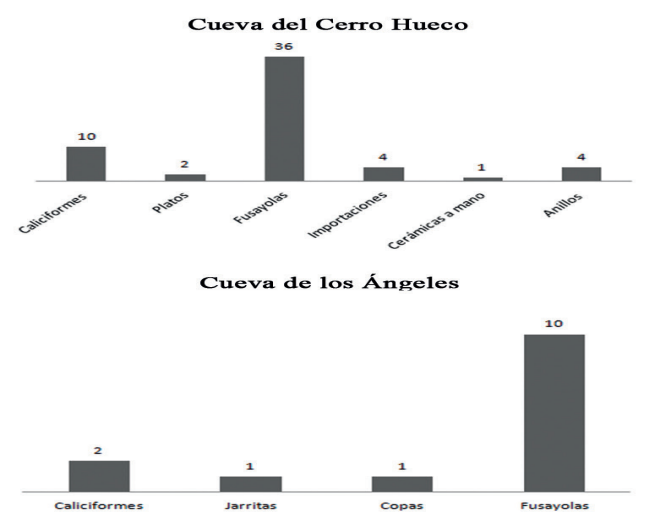

Cueva de los Mancebones

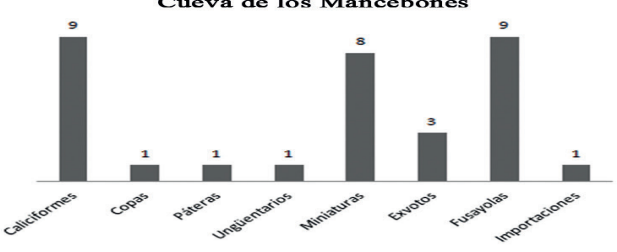

Cueva del Puntal del Horno Ciego II

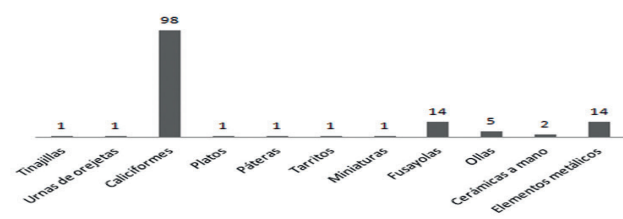

Cueva Santa del Cabriel

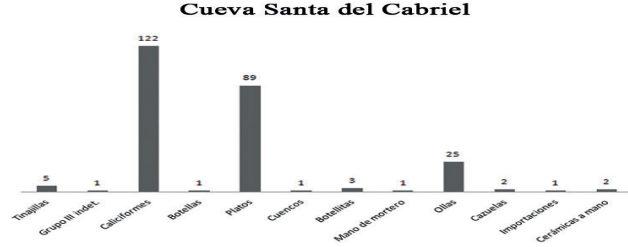

Figura 5. Porcentajes de materiales en cada cueva.

y J. L. Leandro tuvieron la posibilidad de visitar ambas cavidades, decidieron intervenir en la cueva II, ya que en ella encontraron tres caliciformes completos, contaba con un acceso más sencillo y estaba prácticamente inalterada (Gil-Mascarell 1977). Así pues, en septiembre de 1974 se llevó a cabo la intervención (fig. 6.4 y 6.5), cuyos resultados fueron ampliamente publicados por $\mathrm{M}^{\mathrm{a}}$. A. Martí Bonafé (1990), reflejando perfectamente las características de la excavación, así como el registro material documentado. Tras la excavación, las cuevas fueron visitadas en 2002 dentro del proyecto de prospección del término municipal de $\mathrm{Vi}$ llargordo del Cabriel por parte de A. J. Lorrio, G. Molina y T. Pedraz, del cual derivan los planos de ambas cuevas (fig. 3.3), y en 2016 por parte de nuestro equipo.
La revisión de los materiales depositados en el MPV nos ha permitido actualizar la información fotográfica y realizar ligeras modificaciones sobre el inventario publicado (fig. 5). De los 841 fragmentos asociados a cronología ibérica, documentamos un NMI de 125, la mayoría de cocción reductora $(81 \%)$, de los cuales 99 son vasos caliciformes (uno de ellos realizado a mano) (fig. 4.1). Es interesante indicar que el $57 \%$ de estos vasos presentan orificios pares en el borde, realizados pre-cocción, en un solo lado del recipiente. Además, dos de las bases de caliciformes están recortadas, del mismo modo que ocurre con las bases áticas de Cerro Hueco. También hemos documentado algunos elementos que no habían sido recogidos en las publicaciones previas, como termoalteraciones o huellas de uso, así como restos de ocre en el interior de algunos vasos. Destacamos, además, la presencia de 14 fusayolas y dos anillos decorados (fig. 4.2 y 4.8). En nuestro cómputo no incluimos el NMI de restos de fauna, ya que éstos todavía no han sido estudiados en profundidad, siendo tan solo objeto de un estudio preliminar (Sarrión 1990). Los restos humanos tampoco han sido estudiados ni datados, aunque aquellos que se hallaron en los niveles de contacto entre materiales de época ibérica y de la Edad del Bronce, fueron revisados parcialmente por A. Pérez y S. Sancho con el objetivo de obtener una comparativa con la Cueva del Sapo (Machause et al. 2014: 165-168). El conjunto de materiales indica tres momentos distintos de frecuentación: Paleolítico Medio, Edad del Bronce y, principalmente, época ibérica (Martí Bonafé 1990). La presencia de cerámicas a mano, urna de orejetas y las características formales de los caliciformes permite datar la frecuentación ibérica de esta cueva entre los ss. VI-IV a.C. (Martí Bonafé 1990: 160).

La Cueva Santa del Cabriel, también conocida como Cueva Santa de Fuencaliente (Lorrio 2001), Cueva Santa de Mira (Quixal 2008) o Cueva Santa II (Mata et al. 2001), se encuentra a $860 \mathrm{msnm}$ en el curso medio del Cabriel, concretamente en el Barranco de la Cueva Santa, cerca de donde se situaba la aldea de Fuencaliente hasta la construcción del embalse de Contreras (Moya 1998). Debido a la perduración del culto en este espacio hasta la actualidad $^{3}$, es fácilmente accesible a través de peldaños excavados en la roca y una escalera metálica. La boca, orientada hacia el Noroeste, tiene una altura de 1,60 $\mathrm{m}$ y una anchura de $1 \mathrm{~m}$ 
(fig. 3.4). A través de ésta se recorre un pasillo de unos $11 \mathrm{~m}$, el cual fue ampliado para facilitar el acceso a finales del s. XVIII (Moya 1998: 30), pasando a una sala principal de unos $30 \mathrm{~m}$ de ancho y unos $10 \mathrm{~m}$ de alto. De esta surgen varias salas secundarias y gateras en los niveles inferiores, donde se documentaron la mayoría de materiales. Así pues, aunque no ha sido objeto de ninguna excavación arqueológica, contamos con informaciones sobre varios momentos de recogida de materiales. La conocida como
"Misión rescate", formada por colegiales, recogió un conjunto de entre 30 y 40 caliciformes, algunos platos y restos óseos, que se encuentran en colecciones privadas. En los años 70, por desgracia, se expolió por completo con ayuda de explosivos (Moya 1998). Sin embargo, tenemos constancia de otras recogidas de materiales en superficie: en 1974 por parte de I. Sarrión, en 1998 por C. Mata, y la anteriormente citada prospección intensiva en 2003 por el equipo de A. J. Lorrio (Lorrio et al. 2006).

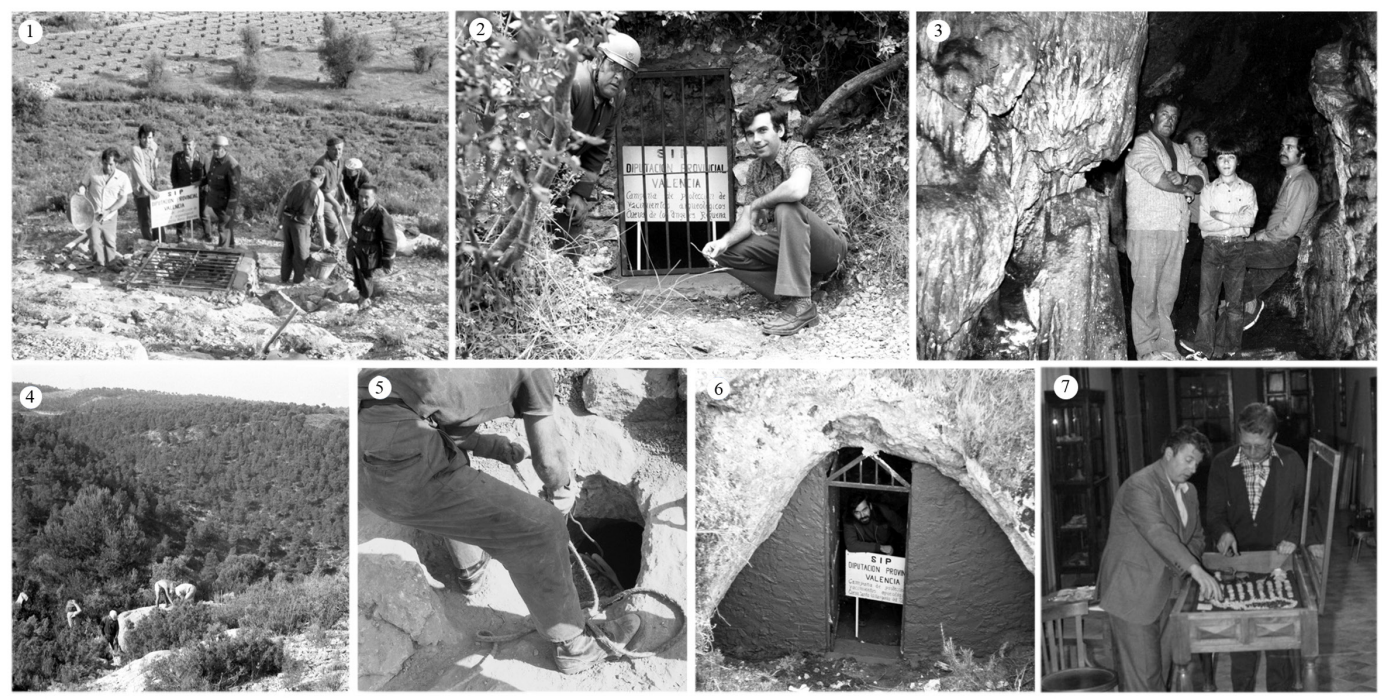

Figura 6. Fotografías antiguas de las cuevas (Archivo Fotográfico del SIP): 1. Cerro Hueco; 2 y 3. Cueva de los Ángeles; 4 y 5. Puntal del Horno Ciego II; 6. Cueva Santa de Villargordo; 7. Museo de Requena.

Por una parte, la revisión de los fondos del MPV nos ha permitido conocer materiales inéditos procedentes de la prospección de I. Sarrión. Y por otra, el estudio de los materiales depositados en el Museo de Cuenca nos ha posibilitado la actualización gráfica de los mismos. Además, F. Moya nos ha autorizado a estudiar su colección privada, compuesta principalmente por fragmentos cerámicos recogidos durante las limpiezas de la cavidad previas a las romerías anuales. Son tanto los ya revisados por A. Lorrio (Lorrio et al. 2006), como los recogidos con posterioridad a 2005 , entre los que destaca una mano de mortero miniaturizada (fig. 4.6). Si tenemos en cuenta el conjunto de materiales hallados, considerando incluso los 30 caliciformes recogidos en los años 60 , observamos que existe una gran acu- mulación de este tipo de vasos, así como de platos (fig. 5). La cueva ha sido frecuentada desde el Bronce Final hasta la actualidad. En lo que respecta a época ibérica, sabemos por las importaciones que, al menos, estuvo frecuentada hasta los ss. II-I a.C. Sin embargo, al igual que en los casos anteriores, abogamos por encuadrar las prácticas rituales entre los ss. V-III a.C.

\section{Otras cuevas con materiales ibéricos}

A los cinco yacimientos anteriores podemos sumar otro grupo de cuevas con materiales ibéricos que, bien por la entidad de su registro material o bien por la mala conservación del mismo, no parecen tener carácter ritual. En primer lugar, tenemos la Cueva de El Molón, situada a los pies del importante 
poblado con el mismo nombre (Lorrio et al. 2001 y 2007) y que actualmente se encuentra tapiada por una fuente de obra. Tan solo contamos con las descripciones y los materiales que se recogieron durante la limpieza del interior de la fuente en 1996, así como en el pequeño sondeo a la entrada de la cueva (Moneo 2001). El registro material es escaso, con 12 fragmentos de cerámica (NMI: 8), siendo además muy heterogéneo en cuanto a tipos y no presentando ningún patrón concreto. Consideramos que no se puede realizar interpretación alguna sobre su uso en época ibérica, aunque no dudamos de su relación con el poblado y las evidencias de hábitat disperso documentadas en la ladera.

En el caso de la Cueva Santa de Villargordo del Cabriel, sin embargo, sí que pudimos acceder a su interior en 2016, documentando materiales ibéricos en superficie (fragmentos de caliciformes, alguna olla de cocina y abundantes restos de fauna). Los materiales ibéricos, provenientes de intervenciones previas (prospecciones de J. Aparicio y de C. Mata) (fig. 6.6), depositados en el MPV en los años 90, se limitan a 16 fragmentos de cerámica (NMI: 4). Sin embargo, las evidencias en superficie, la presencia de sedimento arqueológico y las características físicas del interior (dos salas con formaciones kársticas e innumerables oquedades), son elementos que hacen de esta cueva un yacimiento a tener en cuenta de cara a futuros estudios sobre ritualidad.

De la Cueva del Collado de la Plata únicamente contamos con la referencia de T. Moneo (2001), sin especificar qué tipo de materiales se hallaron ${ }^{4}$. Esta cueva también se encontraría en las inmediaciones de un importante poblado fortificado, el Collado de la Plata o Plaza de Sobrarías (Lorrio 2007: 232-233). Finalmente, aunque tuvimos la posibilidad de revisar los materiales ibéricos de la Cueva de la Tejeda, procedentes de una intervención dirigida en 2003 por J. M. Martínez García y depositados en el Museo de Cuenca, hemos decidido no incluirlos en este estudio, ya que las intervenciones llevadas a cabo estos últimos años bajo la dirección de J. V. Pérez de la Sierra permanecen todavía inéditas (M. Barril c.o.). Además, la cantidad y tipología de los materiales (99 fragmentos, NMI: 8), no eran suficientes para conocer el tipo de actividades llevadas a cabo allí.

\section{Las cuevas como elementos integrados en el territorio}

En las siguientes líneas vamos a analizar las cuevas anteriormente descritas dentro del paisaje y territorio del que forman parte. Tal y como hemos indicado en la introducción, durante las últimas dos décadas se han multiplicado los estudios que buscan superar el enfoque monográfico de las cuevas como meros puntos (características de la cueva y materiales), pasando a valorarlas como verdaderos hitos territoriales, estrechamente ligados con la organización espacial de las comunidades que llevaron a cabo los rituales en su interior (Grau 2002; Grau y Olmos 2005; López-Mondéjar 2010, 2015; Rueda 2011; Amorós 2012; Grau y Amorós 2013).

Para ello, utilizamos modelos de Arqueología del Territorio de esta zona ya publicados, sobre todo desarrollados mediante el empleo de SIG (GRASS y GVSIG). Nos centraremos especialmente en cuestiones de densidad de poblamiento, posibles vías de comunicación y existencia de límites y fronteras entre los territorios. Para un mejor conocimiento de estas cuestiones, en especial sobre su vertiente metodológica, remitimos a publicaciones precedentes (Moreno 2011; Quixal 2012, 2015).

Un simple vistazo al mapa del territorio estudiado permite ver como en la distribución de las cuevas se genera un extenso vacío central (fig. 1). Las cuevas se ubican en los extremos naturales de la meseta, concretamente en tres puntos cardinales: Norte, Este y Oeste. Es por ello que hayamos decidido desglosar el análisis espacial en esas tres partes.

\section{El límite oriental: Las Cabrillas y el valle del Magro}

Del cómputo de cuevas anteriormente tratadas, encontramos dos en el Este de la comarca: Cueva de los Ángeles y Cerro Hueco (fig. 7). No están excesivamente distantes entre sí $\mathrm{y}$, como hemos visto, presentan una serie de características comunes en cuanto a ajuares.

La Cueva de los Ángeles se encuentra al lado del curso del Magro, justo en uno de los tramos en los que el río transcurre más encajado en plena sierra de Las Cabrillas, poco antes de abrirse en el corredor de Hortunas generando una óptima zona de paso. El poblamiento a su alrededor fue bastante escaso, en parte motivado por el carácter agreste del paisaje. El núcleo habitado más próximo sería la atalaya 
del Puntal de Eduardo (Requena, Valencia), de ocupación entre los ss. VI-IV a.C., y, por lo tanto, coincidente en el tiempo con las frecuentaciones de la cueva. Se trata de un pequeño asentamiento fortificado localizado un poco más al Sur de la cavidad, en una cima con am- plio dominio visual sobre el río (Quixal 2013: 295). Más cerca se encuentra aún El Castillejo (Requena, Valencia), un yacimiento muy interesante y de cronología dudosa, ya que a unas construcciones ciclópeas se asocian escasos materiales, tanto a mano como ibéricos.

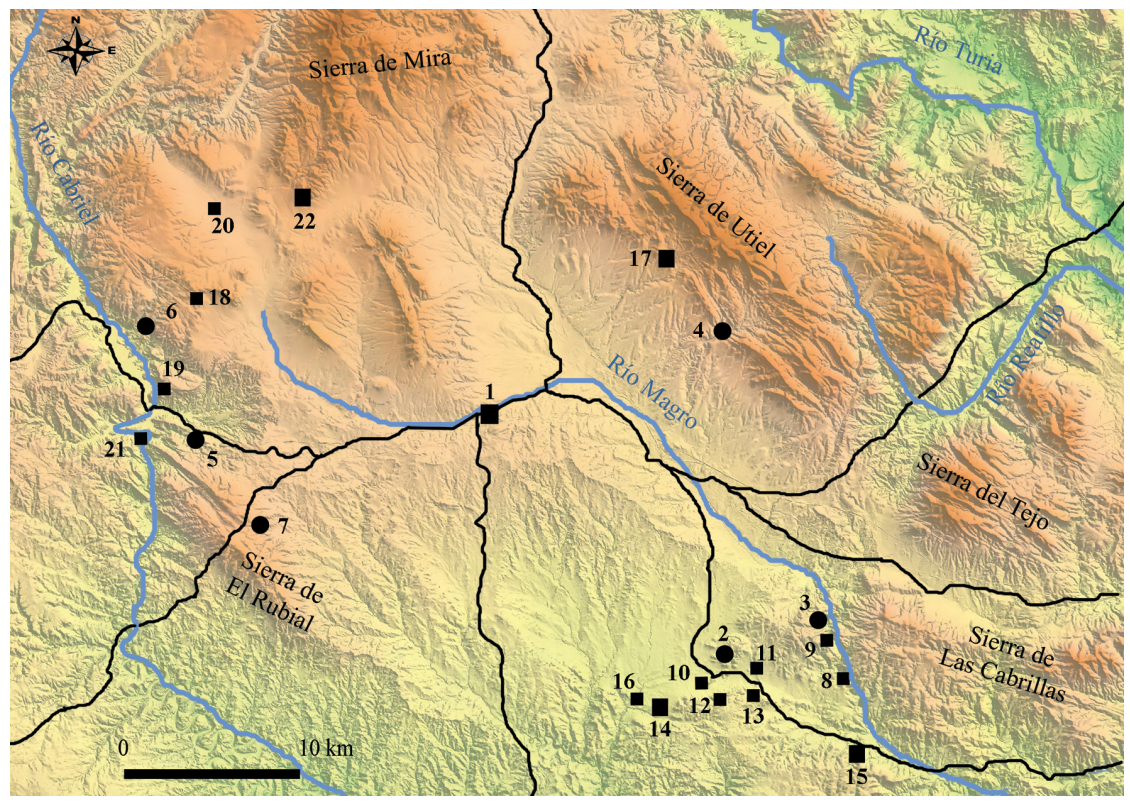

Figura 7. Mapa donde se vinculan las cuevas con las rutas óptimas y el resto de yacimientos citados en el texto: 1. Kelin; 2. Cerro Hueco; 3. Cueva de los Ángeles; 4. Cueva de los Mancebones; 5. Puntal del Horno Ciego II; 6. Cueva Santa del Cabriel; 7. Cueva Santa de Villargordo; 8. Puntal de Eduardo; 9. El Castillejo; 10. Cerro Gallina; 11. Casa Alarcón; 12. Pozo Robledo; 13. Los Alerises; 14. Cerro de la Cabeza; 15. Castellar de Hortunas; 16. Casa de la Cabeza; 17. La Mazorra; 18. Casas del Alabú; 19. Castillejo del Pajazo; 20. Cañada de Mira; 21. Castillo de Minglanilla; 22. El Molón.

Por otro lado, Cerro Hueco se localiza en Las Serratillas, un pequeño grupo de montañas, estribaciones de Las Cabrillas, justo en el punto en que el corredor de Hortunas se abre en el extenso llano de Campo Arcís. De todos los ejemplos aquí tratados es, sin duda, el que tiene un poblamiento más denso a su alrededor. En su radio más inmediato existen diversos yacimientos ibéricos de escasa entidad como Cerro Gallina, Casa Alarcón o Pozo Robledo (Requena, Valencia). El núcleo estable más cercano lo tenemos en Los Alerises, un asentamiento rural de larga diacronía y relativa entidad, justo en la cabecera del corredor de Hortunas (Quixal 2012: 190, 2013: 295). Del mismo modo, la cueva se encuentra entre dos poblados fortificados importantes, el Cerro de la Cabeza y el Castellar de Hortunas (Quixal 2013: 295), aunque bastante más cerca del primero $(4 \mathrm{~km})$ que del segundo $(9,5 \mathrm{~km})$. Por último, cabe mencionar la presencia en dicho llano del asentamiento rural de la Casa de la Cabeza (Quixal et al. 2010; Quixal 2015: 46$60)$, si bien la cronología del mismo es tardía (s. II a.C.) y se encuentra alejado $(4,5 \mathrm{~km})$.

En ambos casos, las ubicaciones han sido relacionadas con la existencia de una importante vía de comunicación pretérita, que seguía el valle del Magro y entraba en la Meseta de Requena-Utiel por el corredor de Hortunas. En trabajos previos, hemos defendido esta ruta como la principal durante la Edad del Hierro (Quixal 2012 y 2013). El camino serviría para comunicar los territorios de La Carència (Torís, Valencia) y Kelin, a nivel regional, pero también sería una escala dentro de una vía mayor entre la costa (Portus Sucronem, la desembocadura del Xúquer) y el interior meseteño (Quixal 2015: 164-166). Pero no sólo eso. A su vez, ambas cuevas se encuentran en las estribaciones (Cerro Hueco) o directamente en plena sierra de Las Cabrillas (Cueva de los 
Ángeles), formación que marca un claro límite natural entre la Meseta y la Hoya de Buñol. En recientes trabajos se ha planteado que dicho límite, del mismo modo, actuaría de frontera entre los territorios de Kelin y su vecino oriental, La Carència. Esta idea parte del análisis de los Polígonos Thiessen y se apoya en toda una serie de variables directamente ligadas con el patrón de asentamiento de la zona (Quixal 2013: 300-301) (fig. 8).

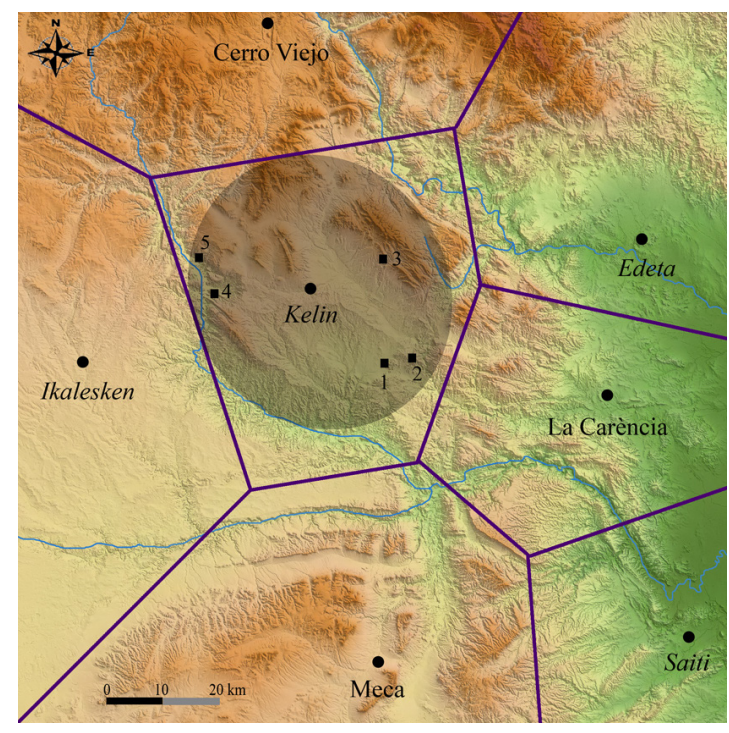

Figura 8. Análisis de Polígonos Thiessen y ubicación de las cuevas rituales: 1. Cerro Hueco; 2. Cueva de los Ángeles; 3. Cueva de los Mancebones; 4. Puntal del Horno Ciego II; 5. Cueva Santa del Cabriel.

La importancia de esta zona y lo significativo de la existencia de dos cuevas-santuario en la misma, motivó la visita y prospección de un elevado número de cuevas, covachas y abrigos en el término de Requena (Quixal et al. 2007). Por lo general, no se localizaron materiales arqueológicos, a excepción de en una pequeña covacha, cerca de la Fuente de la Peseta y la Cueva de los Ángeles, donde se recogieron varios fragmentos cerámicos ibéricos en su boca. No obstante, la escasez de los hallazgos impide plantear hipótesis sobre su uso durante esta época.

\section{El límite septentrional: la sierra de Utiel}

La Cueva de los Mancebones se enmarca en plena sierra de Utiel, entre las sierras menores de El Negrete y Juan Navarro. De nuevo la cavidad está próxima a un curso de agua, en este caso la rambla de Estenas, en el paraje del Requejo. Su boca da directamente a dicho curso irregular de agua. No se trata, para nada, de uno de los sectores de la comarca más poblados en ninguna de las diferentes fases ibéricas. No obstante, destaca la existencia a unos $5 \mathrm{~km}$ de un importante poblado fortificado, $\mathrm{La}$ Mazorra, que desde su posición controla todas las entradas hacia la sierra, así como ese sector septentrional del llano de Utiel (Quixal 2015: 76-77 y 172) (fig. 7).

En este caso la principal vía de comunicación hacia el Norte queda lejos, ya que transcurriría más al Oeste, siguiendo la rambla de La Torre hacia el campo de Sinarcas, zona densamente poblada durante todo el periodo ibérico y romano (Quixal 2015: 167). Por otra parte, la sierra de Utiel aparece cortada por el valle del Reatillo, creando una óptima ruta de paso entre la Meseta de Requena y el Camp de Túria (Moreno 2011: 117-118; Quixal 2015: 166), área asociada con el territorio de Edeta (Llíria, Valencia) (Bernabeu et al. 1987). Pero, del mismo modo, dicha ruta quedaría algo lejos de la ubicación de la cueva, ya que ésta se encuentra justo en un punto intermedio de la sierra de Utiel. No debemos olvidar el carácter de límite natural que dicha sierra tiene para la Meseta de Requena-Utiel y que, por lo tanto, podría de igual forma actuar de frontera entre el territorio de Kelin y los vecinos, Edeta y Cerro Viejo (Moya, Cuenca) (Moreno 2011: 3840; Quixal 2015: 162) (fig. 8).

\section{E1 límite occidental: el río Cabriel y la sierra} de El Rubial

La Cueva Santa del Cabriel y el Puntal del Horno Ciego II se localizan próximos al río $\mathrm{Ca}$ briel, actualmente en el entorno del pantano de Contreras, por lo tanto, una zona geográficamente muy alterada en la última centuria (fig. 7). El curso de este río es el límite geográfico más claro, ya que crea una profunda depresión y genera un gran contraste en altitudes con el resto de la meseta. Es por ello que consideramos que constituiría una frontera también para el territorio de Kelin, tanto por su lado occidental como meridional (Moreno 2011: 38-40; Quixal y Moreno 2011: 15; Quixal 2015: 170) (fig. 8). En este caso lo separaría de su vecino suroccidental, el área de Ikalkusken / Ikalesken (supuestamente Iniesta, Cuenca) (Martínez Valle, 1995).

La Cueva Santa del Cabriel es la única que oficialmente no pertenece a la comarca de Requena-Utiel, si bien la podemos englobar a nivel geográfico por estar en el margen oriental del río. Presenta algunos yacimientos cercanos, como Casas del Alabú y Collado de la 
Cañada (Mira, Cuenca) o el Cerro del Castillo (Minglanilla, Cuenca). No obstante, el poblado ibérico de entidad más cercano es El Molón, núcleo fortificado de gran importancia y objeto de numerosas campañas de excavación (Lorrio et al. 2001; Lorrio 2007), aunque dista más de 10. El propio equipo que realizó las prospecciones en esta cueva, llamó la atención de la práctica ausencia de poblamiento a su alrededor (Lorrio et al. 2006: 66).

Tanto la Cueva Santa como el Puntal del Horno Ciego II, a $6 \mathrm{~km}$ de la primera, se localizan muy próximos a un punto históricamente clave: el vado del Pajazo, uno de los pasos principales sobre el río Cabriel. En recientes trabajos hemos planteado que este vado sería aprovechado por la principal vía Este-Oeste, posibilitando las comunicaciones entre la Meseta de Requena-Utiel y la Meseta castellana (Quixal y Moreno 2011: 18-19). En las proximidades de dicho paso también se ha documentado un poblado de la Edad del Hierro I, de nuevo conocido como El Castillejo, en una escarpada cima que mira directamente al río (Lorrio et al. 2006: 66).

Por su parte, aunque a fecha de hoy no tenemos datos suficientes para otorgarle un carácter sacro, la Cueva Santa de Villargordo también tiene una interesante ubicación. Está emplazada en plena sierra de El Rubial, uno de los elementos geográficos que, junto con la depresión del río Cabriel, delimitan el territorio por el Oeste/Suroeste. Procedentes de dicha sierra recientemente se han publicado una serie de materiales singulares que permiten plantear la existencia de algún tipo de santuario o loca sacra al aire libre (Martínez García 2011). Y, al igual que en los casos anteriores, la cavidad se podría relacionar con otra variante de vía hacia el territorio de Ikalesken (Quixal y Moreno 2011: 19-20) (fig. 7).

\section{Comunidades, rituales y territorialidad}

Por último, vamos a recoger todas las características comentadas a lo largo del presente artículo, con el objetivo de intentar establecer, de manera general, patrones sobre las cuevas del territorio de Kelin, a la par que planteamos si son similares a otros territorios. De nuevo, el análisis se articulará en dos campos que necesariamente van entrelazados: por un lado, la integración territorial de las cuevas y su significado en el paisaje del que forman parte; $y$ por otro lado, los ajuares que presentan y su conexión con los posibles rituales llevados a cabo en las mismas. Muchas de estas variables ya fueron recogidas en las primeras publicaciones de este campo de estudio. No obstante, algunas constituyen poco más que simples tópicos, otras son compartidas tan sólo por unas cuantas cuevas, mientras que otras, a nuestro juicio las más importantes, se pueden asociar a la práctica totalidad de las mismas.

En primer lugar, desde los primeros trabajos sobre las cuevas-santuario ibéricas se resaltó una estrecha relación con el agua (Gil-Mascarell 1975: 74). En la Protohistoria mediterránea tenemos infinidad de ejemplos de culto a las aguas, tradición que dentro de una cueva podía adaptarse a las diferentes variantes geológicas que éstas suelen presentar: aguas subterráneas, nacimiento de un manantial o existencia de formaciones calcáreas (estalactitas, estalagmitas y columnas) (Maggiani 1999). La presencia de agua en el interior de una cueva constituiría un elemento purificador, importante en los posibles rituales llevados a cabo (Moneo 2003). En nuestra zona de estudio ninguna cueva presenta actualmente gran cantidad de agua en su interior y las formaciones kársticas no son excesivamente complejas, si bien no podemos saber si esto era igualmente así hace 2.500 años. Del mismo modo, no contamos con evidencias claras de recogida de agua, a excepción de la cubeta excavada de la Cueva de El Molón (Moneo 2001). Sin embargo, la información con la que contamos hasta la fecha no nos permite realizar apreciaciones sobre la cronología de su construcción, ni sobre el papel del agua en los rituales llevados a cabo en el resto de cuevas.

Pese a todo, podemos enfocar esta relación cultual con el agua de otra forma. La mayoría de las cuevas están próximas a cursos de agua, siendo además éstos los principales de la comarca. De este modo, Puntal del Horno Ciego II y la Cueva Santa están muy cerca del curso del río Cabriel; la Cueva de los Ángeles mira directamente al río Magro y a los pies de la Cueva de los Mancebones fluyen las aguas de la rambla de Estenas. Es por todos conocidos el carácter sacro que se le ha otorgado a este tipo de elementos naturales durante la antigüedad (Edlund 1987: 58-60; Domínguez Monedero 1997: 397), algo atestiguado en la propia comarca de Requena-Utiel con el hallazgo de diversos depósitos votivos en el Cabriel. En este sentido, se han encontrado varios conjuntos de monedas (Martínez Valle 1995), 
una figurita de barro cocido indeterminada y un casco de tipo montefortino (Quixal 2015: 196). Lo complicado es discernir si el carácter sacro de estas cuevas debe plantearse en relación directa con el agua o, como veremos posteriormente, responde más al carácter fronterizo y de zona de paso que dichos ríos acarrean. No es casual que las cuevas se encuentren justamente en las zonas más abruptas de estos cursos y no encontremos ninguna evidencia de ritualidad, por ejemplo, en cuevas existentes cerca de la fértil vega que genera el río Magro en las zonas centrales de la comarca.

Enlazando con esta reflexión, vemos como las cuevas tienen una estrecha relación con importantes caminos y zonas de paso. Es significativo como las cavidades del Cabriel se encuentran cerca de uno de los principales pasos, el Pajazo. En el sector opuesto de la comarca, Cerro Hueco y la Cueva de los Ángeles se relacionan directamente con la importante vía de comunicación del valle del Magro; y la Cueva Santa de Villargordo, aún con dudas, se puede vincular también con una de estas vías hacia el Suroeste. Sin embargo, la Cueva de los Mancebones es el ejemplo que peor entronca con esta idea, quedando alejado de las principales rutas hacia el Norte o Noreste. Son abundantes las referencias a la relación entre este tipo de santuarios y los caminos y zonas de paso (Grau 2002: 219; Edlund 2011: 10) y nuestro estudio parece refrendarlas. Además, las cuevas flanquean las principales vías, aquellas que articulan el territorio y garantizan las comunicaciones con los territorios vecinos.

Pero, si hay alguna variable que consideramos fundamental y compartida por las cinco cuevas de este estudio, es su vinculación con zonas limítrofes y fronterizas (Quixal 2012: 202; 2013: 200; 2015: 195-196). Puntal del Horno Ciego II y Cueva Santa del Cabriel enlazan muy bien con el límite Oeste, claramente definido por el río Cabriel; Los Mancebones se enmarca en plena sierra de Utiel, límite natural septentrional; y Cerro Hueco y la Cueva de los Ángeles se encuentran en la sierra de Las Cabrillas, uno de los límites geográficos más claros por el Este, que marcan la transición entre la Meseta de Requena y la Hoya de Buñol. Además de ser unos límites geográficos claros para la meseta, en época ibérica constituirían los confines del territorio de Kelin; en concreto las fronteras con las ciudades vecinas de Cerro Viejo (Norte), Edeta y La Carència (Este) e Ikalesken (Oeste) (Moreno 2011; Quixal 2015), aunque es complicado conocer la entidad de todas ellas. El Sur, supuesto límite con el territorio de Castellar de Meca (Ayora, Valencia), quedaría claramente establecido con el curso del Cabriel, pero no encontramos ningún ejemplo de cueva en ese sector, tan sólo los depósitos votivos anteriormente citados. Las cuevas, por lo tanto, sacralizarían los límites territoriales, algo fundamental para asegurar la cohesión de las comunidades de su interior. Eran santuarios de frontera, donde la pertenencia a una determinada comunidad se expresa con más fuerza, precisamente por este carácter de transición.

I. E. M. Edlund (1987), para el caso de Etruria, y F. De Polignac (1984), para Grecia, fueron los autores pioneros en señalar la existencia de determinados santuarios extraurbanos, dependientes de la ciudad, pero ubicados en espacios alejados, en los límites de los diferentes territorios. Dichos santuarios, además, acarreaban un fuerte contenido simbólico por ubicarse en importantes barreras geográficas como montañas singulares o cursos de agua. Actuaban como hitos marcadores para diferenciar las tierras del interior (lo civilizado, sagrado y conocido) del espacio exterior (lo salvaje, secular y desconocido), a la par que constituían puntos estratégicos a nivel geopolítico.

En el mundo ibérico existen ejemplos paradigmáticos de santuarios de frontera, tanto en cueva (Collado de los Jardines, Santa Elena, Jaén) (Rueda 2011) como al aire libre (El Pajarillo, Huelma, Jaén) (Ruiz Rodríguez et al. 2000). No obstante, sin duda los paralelos más claros e inmediatos los encontramos en los trabajos de I. Grau en las comarcas centrales alicantinas (Grau 1996, 2002; Grau y Olmos 2005), a los que sumamos las recientes investigaciones compartidas con I. Amorós (Amorós 2012; Grau y Amorós 2013). Las cuevas-santuario consagran los confines de los oppida, marcando los límites territoriales y diferenciándose de los vecinos.

Una última variable que hemos observado, pero en este caso de forma negativa, es la lejanía respecto a asentamientos de importancia. Es una tónica repetida la práctica ausencia de poblamiento alrededor de las cinco cuevas, al menos si hablamos de núcleos con un tamaño significativo. Este hecho ya fue detectado en trabajos anteriores (Gil-Mascarell 1975: 324-325; Lorrio et al. 2006: 67-69), relacionándose con el carácter aglutinador y de centros de atracción que tenían estos lugares, de ahí su posición intermedia y equidistante de varios poblados. Es 
el concepto de political sanctuaries desarrollado por I. E. M. Edlund (1987: 41-42), santuarios como puntos neutrales, compartidos por personas o grupos provenientes de diferentes asentamientos. Por ello, pensamos que en este modelo sería incoherente su establecimiento próximo y directo a los principales poblados, de ahí que descartemos como lugares de culto algunas de las cuevas ligadas a poblados, como puedan ser las de El Molón y Plaza de Sobrarías. No dudamos que puedan presentar material y que se hiciese un uso de las mismas de forma coetánea a los poblados (ganado, almacén, refugio, etc.). Pero el registro material, hasta el momento, no indica que dichos usos fuesen rituales.

En cuanto a los ajuares de las diferentes cuevas, aunque aquí no es nuestro objetivo analizar las actividades específicas desarrolladas en cada cueva, sí que conviene recalcar, al menos, tres aspectos que evidencian un uso ritual de las mismas. Por un lado, es interesante destacar la repetición de un mismo tipo de ofrenda en varias cavidades (fig. 5): una de las huellas más visibles en el registro arqueológico para detectar estas actividades. Tal y como indica C. Bell (1997: 138), una acción puede convertirse en ritualizada cuando se produce repetidamente, respetando unas normas y un formalismo determinado y siguiendo unas tradiciones marcadas, cargadas de simbolismo. Así pues, es interesante observar como los objetos hallados en estas cuevas, no son objetos votivos en sí mismos, es decir, confeccionados con el objetivo de ser depositados en un contexto sacro; sino que son elementos utilizados en la vida cotidiana que se ritualizan al ser depositados a través de un formalismo determinado, en un contexto ritual.

En el territorio de Kelin se repiten, principalmente, dos pautas. La más generalizada es la acumulación de vasos caliciformes, que documentamos en el Puntal del Horno Ciego II (99) y en la Cueva de los Mancebones (9), los cuales comparten protagonismo en el caso de la Cueva Santa del Cabriel (122) con otros recipientes cerámicos como los platos (89) o las ollas (25). La segunda pauta, repetida en cuatro de las cinco cuevas, es la acumulación de fusayolas. El caso más evidente es el de Cerro Hueco, con más de 200. Sin embargo, también están presentes en un número bastante representativo en el Puntal del Horno Ciego II (10), en la Cueva de los Ángeles (10) y en la Cueva de los Mancebones (9), estando ausentes en la Cueva Santa del Cabriel. Estas repeticiones se reproducen en otras cuevas del mundo ibérico, pero no siempre con las mismas normas. Bien es cierto que los caliciformes son una de las ofrendas más evidentes en cuevas como la de Merinel (Bugarra, Valencia) (Martínez Perona 1992), la Cueva de la Moneda (Ibi, Alicante) (Cerdà 1996) o la Cova de l'Aüela (Vall d'Alcalà, Alicante) (Amorós 2012), entre otras. Sin embargo, contamos con otro tipo de repeticiones como las ollas, en el caso de la Cova dels Pilars (Agres, Alicante) (Grau 1996); las ofrendas de cerdos y ovicaprinos infantiles en la Cueva Merinel (Bugarra, Valencia) (Blay 1992) o de ciervos y ovicaprinos en la Cueva del Sapo (Chiva, Valencia) (Machause y Sanchis 2015); y la acumulación de exvotos de bronce en el caso de las cuevas de Alto Guadalquivir (Rueda 2011).

Los recipientes cerámicos ibéricos, tanto caliciformes como ollas y platos, pueden concebirse como objetos votivos en sí, aunque seguramente actuaron como contenedores de ofrendas de alimentos y líquidos, bien mediante simple deposición, bien formando parte de banquetes rituales o libaciones (Izquierdo 2003; Grau y Amorós 2013: 199). Además, en ocasiones se ha planteado que los caliciformes en estos contextos, en especial los que presentan cocción reductora, restos de quemado y agujeros pre-cocción, podían servir como lámparas de aceite, para iluminar de forma simbólica estos espacios (Martínez Perona 1992). En la Cueva de los Mancebones y el Puntal del Horno Ciego II se han documentado caliciformes con estas características.

Por otro lado, la abundancia de fusayolas en las cuevas del Cerro Hueco y Los Ángeles, ha sido relacionada con una elevada producción textil en la zona, que pudiese desembocar en algún tipo de culto al respecto (Martínez Valle y Castellano 1996). Piezas de telares son frecuentes en santuarios por todo el Mediterráneo (Gleba 2009). Generalmente asociadas a las mujeres, pueden ser interpretadas como ofrendas dentro de rituales de paso (por edad o matrimonio), peticiones de protección de la actividad textil, objetos atados a las prendas de ropa ofrendadas (y no conservadas) e, incluso, como producto de una actividad textil ritual in situ. En nuestro caso llama la atención su tamaño, por lo general bastante pequeño, y el hecho de que muchas aparezcan decoradas, algo que no suele ocurrir en ámbito doméstico, pero sí en ámbito funerario y sacro. Ambos aspectos, sumados a su gran concentración en 
Cerro Hueco, nos hacen plantear la posibilidad de que quizás algunas formasen parte de elementos ornamentales, funcionando a modo de cuentas de collar, algo imposible de demostrar por la no conservación del hilo o cordel. Del mismo modo, la ofrenda de anillos y joyas, como las documentadas en Cerro Hueco o Puntal del Horno Ciego II (fig. 4.5 y 4.8), también se ha relacionado con las prácticas iniciáticas que se podrían desarrollar en estos espacios (Grau y Amorós 2013: 199).

En segundo lugar, hay que destacar la presencia de importaciones en al menos tres de las cuevas: de origen ático en el Cerro Hueco (dos bases recortadas y dos páteras L24 y L24/25) y en la Cueva de los Mancebones (una pátera); y de origen itálico en la Cueva Santa del Cabriel (dos fragmentos informes de Campaniense A). Estas cerámicas formarían parte de alguno de los depósitos votivos realizados en dichas cuevas. Cualquier elemento que tenga un valor intrínseco para un individuo o una comunidad puede convertirse en ofrenda. $\mathrm{Su}$ valor dependerá de cada acto y tradición propia, estando cargadas de una importante implicación social (Barrial 1990). Aunque la cerámica indígena es la más repetida en este tipo de contextos, la presencia de importaciones acrecentaría el simbolismo ritual de la ofrenda (Bonet y Mata 1997). De hecho, en algunos casos, la decoración que presentan se ha relacionado con el tipo de ritual llevado a cabo en la cueva (Grau y Olmos 2005).

Por último, nos gustaría hacer una pequeña reflexión sobre las imágenes presentes en las cuevas analizadas, ya que éstas pueden informarnos sobre las actividades rituales llevadas a cabo en estos contextos. Son cinco los ejemplos con los que contamos, en tres de las cuevas: un grifo, varias aves y un motivo floral o soliforme. La representación del grifo, la hallamos en una de las bases áticas recortadas de Cerro Hueco (fig. 4.4); también de esta cueva procede una fusayola decorada con la figura de un ave y un motivo indeterminado, posiblemente un símbolo vegetal o solar (fig.4.7); de la Cueva Santa del Cabriel, contamos con una mano de mortero miniaturizada con cabeza de ave (fig. 4.6); mientras que los anillos de bronce con chatón hallados en Puntal del Horno Ciego II, ambos con misma técnica decorativa, muestran dos aves y un símbolo solar o floral (fig. 4.8).

La representación de grifos, tanto sobre cerámica griega como ibérica, se ha documentado en varios yacimientos ibéricos, mayoritaria- mente en contextos rituales y funerarios (Ramos 1997). La base recortada del Cerro Hueco presenta un prótomo de grifo con las fauces abiertas surgiendo de la tierra, rodeado de elementos acuáticos y florales que podían asociarse con la cueva. En el contexto simbólico en el que nos encontramos, este ser fantástico podría constituir el demon o monstruo del lugar al que debía enfrentarse el iniciado para superar la prueba a la que era sometido (apéndice de González-Alcalde en Grau y Olmos, 2005). La grifomaquia o la lucha del hombre contra seres fantásticos y feroces, en general, es uno de los relatos heroicos que se repiten en la iconografía ibérica, siempre relacionada con los varones. El grifo adopta, generalmente, dos actitudes: protector del difunto en su camino al reino de los muertos o monstruo terrorífico al que el varón debe enfrentarse en un combate heroico (Ramos 1997; Mata et al. 2014: 137-141, 188-193).

Sin embargo, la representación de aves en la iconografía ibérica, se relaciona con la imagen femenina, sobre todo en la esfera ritual (Prados 2004; Izquierdo 2008), excepto las rapaces y las aves que se representan en escenas más complejas, que se asocian, generalmente, con la esfera masculina (Mata et al. 2014: 7073). Las aves, y en concreto las palomas, ofrecidas o acompañantes, aparecen tanto en la escultura, en los exvotos de bronce y la cerámica vascular ibérica, como en elementos asociados con las mujeres: alfileres, peines o colgantes (Mata et al. 2014: 214; Gualda 2015). Éstas sirven de conexión con la esfera supraterrenal y son un claro símbolo de la divinidad femenina vinculada a la fertilidad (Olmos y Tortosa 2010: 243). En el contexto de Puntal del Horno Ciego II, Cerro Hueco y la Cueva Santa del Cabriel, puede simbolizar tanto el género del oferente, como de la divinidad. Así pues, estas imágenes estarían en relación con los ritos de paso femeninos llevados a cabo en el interior de las cavidades, en una de las cuales, además, se documentan altas concentraciones de fusayolas, exponentes del género femenino (Izquierdo 2008: 127-128); sin embargo, también pueden simbolizar la imagen de la divinidad a la que se ofrecen dichas piezas, sancionando con su presencia los ritos de paso (Prados 2004). Sea como fuere, la representación de las aves en espacios rituales como las cuevas, es una pauta que está presente tanto en el territorio de Kelin, como en cavidades de otras zonas: la Cueva de la Torre del Mal Paso (Castellnovo, Castellón) (Fletcher 1954: fig. 10), la 
Cova dels Pilars (Grau 1996: 94) o la Cueva de la Nariz (Umbría del Salchite, Murcia) (Ocharán 2015), entre otras. Un código temático y simbólico común, que puede indicar un ritual, una divinidad, un objetivo y/o un grupo social similar.

Por último, aunque la identificación de los símbolos de la fusayola de Cerro Hueco y del motivo presente en el chatón de uno de los anillos de Puntal del Horno Ciego II, es bastante complicada, pensamos que puede ser algún motivo floral o solar. El simbolismo del Sol pudo estar en relación con la iluminación de la cavidad en determinado momento del día o del año. La utilización de los espacios rituales ibéricos en determinadas ocasiones, como los equinoccios, ha sido propuesta en varias ocasiones (Esteban 2013). Sin embargo, no contamos con estas observaciones en relación a las cuevas estudiadas.

\section{Conclusiones}

El territorio de Kelin constituye un marco idóneo para el estudio de las cuevas-santuario, por su cantidad, por sus características y por la riqueza de sus materiales. Dentro del conjunto de cuevas con materiales ibéricos, las cinco que consideramos a día de hoy como claros ejemplos de ritualidad, presentan una serie de patrones bien definidos: proximidad a cursos de agua, vinculación con caminos e importantes vías, ubicación en zonas fronterizas, ausencia de poblamiento de entidad a su alrededor, ajuares dominados por uno o varios tipos de objetos, iconografía simbólica, reutilización de espacios con ocupaciones de épocas anteriores que pueden indicar una perduración de la memoria (generalmente cuevas sepulcrales de las Edades del Cobre y/o del Bronce), etc. Aunque algunas de estas características son compartidas con otras zonas, no creemos que pueda plantearse como un modelo general, ya que cada territorio consta de dinámicas y problemáticas poblacionales propias.

Algunas de estas cuevas han perdurado como lugares de culto, adaptándose a las nuevas religiones, pero continuando su papel como centros aglutinadores y catalizadores de diferentes comunidades que los visitan de forma ocasional, a modo de romería. Así ocurre en la Cueva Santa del Cabriel (Moya 1998; Lorrio et al. 2006) y, de confirmarse, también en la Cueva de la Virgen de Tejeda (Martínez Gar- cía 2002). No obstante, tal y como ya apuntó J. González-Alcalde (1993: 77), consideramos que, por lo general, las cuevas tienen un espacio limitado y una topografía compleja, lo que dificulta que los rituales fuesen llevados a cabo por grandes colectivos, al menos aquellos que se realizaran en el interior de la cueva (Machause y Sanchis 2015: 279-281). Eso, y lo limitado del registro material para las amplias diacronías que manejamos, nos hacen pensar que sólo un segmento de la población tendría acceso a los mismos, y dicho segmento seguramente formaría parte de las clases altas y dirigentes. La idea de que se realizarían rituales de iniciación o de paso, tanto masculinos como femeninos, en estos lugares sacros que a su vez marcan la transición entre dos territorios, es la hipótesis actualmente más aceptada (Moneo 2003: 386; Grau y Amorós 2013).

El desarrollo de estos espacios sacros, pese a localizarse en zonas alejadas, está muy ligado al propio desarrollo urbano de las comunidades (Edlund 1987: 41). En nuestro caso, es significativo que la eclosión del culto en cueva (s. V a.C.) es coincidente con el crecimiento urbano del lugar central, Kelin, así como el inicio de su proceso de territorialización; la estructuración compleja y jerarquizada de su territorio (Mata et al. 2001; Moreno 2011). Y, precisamente por la misma cuestión, no es casual que el declive de dicho culto sea a partir del s. II a.C., momento en que las estructuras territoriales ibéricas entran dentro del aparato gubernamental romano. A partir de entonces pudieron seguir dándose frecuentaciones y rituales, dado que estos espacios continuarían teniendo un fuerte valor simbólico (acrecentado por centurias de tradición acumulada), pero sin duda la asiduidad en las mismas fue mucho menor, a tenor de los materiales hallados (Quixal 2015: 195-196). Justo en ese momento, el Ibérico Final, es cuando se documentan posibles santuarios rupestres en abrigos de poca profundidad, con inscripciones ibéricas en la roca. Se encuentran en las mismas áreas fronterizas, aunque por el exterior: en el lado occidental del río Cabriel, en el Abrigo de Reiná (Alcalá del Júcar, Albacete); y en el extremo oriental de la sierra de Las Cabrillas, en el Abrigo de El Burgal (Siete Aguas, Valencia) (Pérez Ballester 1992). El nuevo contexto, ya bajo la órbita romana, despojaba de sentido algunos de los usos y significados que quedaban reflejados en los cultos practicados en las cuevas. 
1. El presente artículo entronca directamente con la tesis doctoral de uno de los autores (Machause 2017), desarrollada gracias a una ayuda predoctoral del subprograma "Atracció de Talent" (VLC-CAMPUS), cuyo objetivo principal era comparar los casos específicos de las cuevas situadas en los territorios ibéricos de Kelin, Edeta y Arse. Actualmente dicha temática está teniendo continuidad en una fase postdoctoral (APOSTD-Generalitat Valenciana-Fondo Social Europeo) con el análisis de estos espacios en otros territorios desde una perspectiva material, sensorial y territorial.

2. Agradecemos la colaboración aportada por Fernando Moya, Alberto J. Lorrio, Magadalena Barril, Remedios Martínez y Carmen Rueda. Damos las gracias también a Consuelo Mata, Vanessa Albelda, Paco Blay, Bruno Rives y Pepe Sierra por acompañarnos en la visita a las cuevas.

3. Ninguna de las publicaciones de esta cueva recoge una planta o croquis de la misma.

4. Nosotros mismos participamos en la Romería desde Fuenterrobles en mayo de 2015.

5. Las fuentes consultadas nos han hablado de caliciformes y alguna moneda, así como claras evidencias de expolio en la primera sala (A. Lorrio c.o.).

\section{Bibliografía}

Amorós, I. (2012): La Cova de l'Aüela (Vall d'Alcalà, Alicante). Una cueva-santuario en el corazón de la Contestania Ibérica. Alberri, 22: 51-93.

Aparicio, J. (1976): El culto en cuevas en la región valenciana. Homenaje a García y Bellido, I Revista de la Universidad Complutense, Vol. XXV, $\mathrm{n}^{\circ} 101:$ 9-30.

-; Latorre, F. (1977): Catálogo-guía del museo arqueológico de Requena. Serie Arqueológica, 1, València.

—; San Valero, J.; Martínez, J. V. (1983): Actividades arqueológicas desde 1979 a 1982. Varia, II: 375-378.

Aranegui, C. (1975): La cerámica gris monocroma: puntualizaciones sobre su estudio. Papeles del Laboratorio de Arqueología de Valencia, 11: 333-379.

Barrial i Jové, O. (1990): El ritual de sacrificio en el mundo ibérico catalán. Zephyrus, XLIII: 243-248.

Bell, C. (1997 [2009]): Ritual: perspectives and dimensions. Oxford University Press.

Bernabeu, J.; Bonet, H.; Mata, C. (1987): Hipótesis sobre la organización del territorio edetano en Época Ibérica Plena: el ejemplo del territorio de Edeta/Llíria. Iberos. I Jornada sobre el Mundo Ibérico, Jaén: 137-156.

Blay, F. (1992): Cueva Merinel (Bugarra). Análisis de la fauna. Estudios de Arqueología ibérica y romana. Homenaje a Enrique Pla Ballester (J. Juan Cabanilles, coord.), Serie de Trabajos Varios del SIP, 89, Valencia: 283-287.

Bonet, H.; Mata, C. (1997): Lugares de culto Edetanos. Propuesta de definición. Quaderns de Prehistòria $i$ Arqueologia de Castelló, 18: 115-146.

Canela, J. (2014): Evolució del poblament i el paisatge a la Cesserània Occidental durante el 1r mil·leni a.C. Tesis Doctoral inédita, Universitat Rovira i Virgili.

Cerdà, F. (1996): La Cova de la Moneda (Ibi, Alacant): una cova-santuari ibérica a la Foia de Castalla. Recerques del Museu d'Alcoi, V: 199-202.

Coll, R.; Cazorla, F. y Bayes, F. (1994): El santuari ibèric de la Cova de les Encantades del Montcabrer (Cabrera de Mar, el Maresme). Estudi preliminar. Laietania, 9: 35-85.

De Polignac, F. (1984): La naissance de la cité grecque: cultes, espace et societé VIII-VII siècles avant $J$. - C. Paris.

Domínguez Monedero, A. (1997): Los lugares de culto en el mundo ibérico: espacio religioso y sociedad. Quaderns de Prehistòria i Arqueologia de Castelló, 18: 391-404.

Donat, J. (1966): Catálogo espeleológico de la provincia de Valencia. Memorias del Instituto Geológico y Minero de España, Tomo LXVII, Madrid.

Edlund, I. E. M. (1987): The gods and the place. Location and function of sanctuaries in the countryside of Etruria and Magna Grecia (700-400 BC). Acta Instituti Romani Regni Sueciae, series in 4º, XLIII, Estocolmo.

- (2011): Introduction. The Archaeology of sanctuaries and ritual in Etruria (N. T. Grummond, I. Edlund, eds.), Porstsmouth: 7-15.

Esteban, C. (2013): Arqueoastronomia y religion ibérica. En Rísquez y Rueda 2013: 465-484.

Fernández, J.; Garay, P.; Gimenez, S.; Ibañez, P. A.; Sendra, A. (1982): Catálogo espeleológico del País Valenciano. Tomo II, Federació Valenciana d'Espeleologia. 
Fletcher, D. (1954): La cueva y el poblado de la Torre del Mal Paso (Castellnovo). Archivo de Prehistoria Levantina V: 187-222.

Gil-Mascarell, M. (1971). Yacimientos ibéricos en la Región Valenciana. Estudio del poblamiento (resumen de la Tesis Doctoral), Valencia.

- (1975): Sobre las cuevas ibéricas del País Valenciano. Materiales y problemas. Papeles del Laboratorio de Arqueología de Valencia, 11: 281-332.

- (1977): Excavaciones en la cueva-ritual ibérica de Villargordo del Cabriel (Valencia). XIV Congreso Nacional de Arqueología, Zaragoza: 705-710.

Gleba, M. (2009): Textile tools in ancient italian votive contexts: Evidence of dedication or production? Votives, places and rituals in Etruscan religion (M. Gleba, H. Becker, eds.), Brill, Leiden: 69-84.

Gómez Serrano, N. P. (1931): Secció d'Antropologia i Prehistòria. Resum dels treballs de la Secció durant l'any 1930. Anales del Centro de Cultura Valenciana, IV (8): 73-80.

González-Alcalde, J. (1993): Las cuevas santuario ibéricas en el País Valenciano: Un ensayo de interpretación. Verdolay, 5: 67-78.

- (2002-2003a): Cuevas-refugio y cuevas-santuario en Castellón y Valencia: Espacios de resguardo y entornos iniciáticos en el mundo ibérico. Quaderns de Prehistòria i Arqueologia de Castelló, 23: 187-240.

- (2002-2003b): Estudio historiográfico, catálogo e interpretación de las cuevas-refugio y cuevas-santuario de época ibérica en Alicante. Requerques del Museu d'Alcoi, 11/12: 57-84.

- (2005): Cuevas-refugio y cuevas-santuario ibéricas en la región de Murcia. Historiografía, catalogación e interpretación. Verdolay, 9: 71-94.

Grau, I. (1996): La Cova dels Pilars (Agres, El Comtat). Aportació a l'estudi de les coves-santuari ibèroques. Alberri, 9: 78-105.

- (2000): Territorio y lugares de culto en el área central de la Contestania. Quaderns de Prehistoria i Arqueologia de Castelló, 21: 195-225.

- (2002): La organización del territorio en el área central de la Contestania Ibérica. Serie Arqueológica, Alicante.

-; Olmos, R. (2005): El ánfora ática de la Cova dels Pilars (Agres, Alicante): Una propuesta de lectura iconográfica en su contexto espacial ibérico. Archivo Español de Arqueología, 78: 49-77.

-; Amorós, I. (2013): La delimitación simbólica de los espacios territoriales: el culto en el confín y las cuevas-santuario. En Rísquez y Rueda (2013): 183-212.

Gualda, R. M. (2015): Representación y presencia del ave en la cultura ibérica. Su análisis en el ámbito funerario. I Encuentro de Jóvenes Investigadores en Arqueología de la Región de Murcia: de la arqueología prehistórica a la arqueología industrial (A. Fernández Díaz, ed.), Universidad de Murcia: 227-270.

Izquierdo, I. (2003): La ofrenda sagrada del vaso en la cultura ibérica. Zephyrus, 56: 117-135.

- (2008): Arqueología, iconografía y género: códigos en femenino del imaginario ibérico. Verdolay, 11: 121-142.

López-Bertran, M. (2015): Paisajes rituales en el Sucronensis Sinus. El Sucronensis Sinus en época ibérica (C. Aranegui, coord.), Saguntum Extra, 17: 43-62.

López-Mondéjar, L. (2015): Lugares de culto ibéricos en el área murciana: revisión crítica y nuevos planteamientos para su estudio en el sureste peninsular. Cuadernos de Arqueología de la Universidad de Navarra, 23: 181-224.

Lorrio, A. J. (2001): La arqueología ibérica en la comarca de Requena-Utiel: análisis historiográfico. Los iberos en la comarca de Requena-Utiel (Valencia) (A. J. Lorrio, ed.), Serie Arqueológica, Alicante: $15-31$.

- (2007): El Molón (Camporrobles, Valencia) y su territorio: fortificaciones y paisaje fortificado de un espacio de frontera. Paisajes fortificados de la Edad del Hierro. Las Murallas protohistóricas de la Meseta y la vertiente atlántica en su contexto europeo (L. Berrocal, P. Moret, eds.), Bibliotheca Praehistorica Hispana, 28, Madrid: 213-235.

Lorrio, A.; Molina, G.; Pedraz, T. (2002): Patrimonio cultural arqueológico de Villargordo del Cabriel, Memoria de prospección. Lorrio, A. J.; Moneo, T.; Moya, F.; Pernas, S.; Sánchez De Prado, Ma . D. (2006): La Cueva Santa del Cabriel (Mira, Cuenca): Lugar de culto antiguo y ermita cristiana. Complutum, 17: 45-80.

Lucas, R. (1981): Santuarios y dioses en la Baja Época Ibérica, La Baja Época en la Cultura Ibérica. Actas de la mesa redonda celebrada en conmemoración del X aniversario de la AEAA, Madrid, 233-293. 
Machause, S. (2017): Las cuevas como espacios rituales en época ibérica. Los casos de Kelin, Edeta y Arse. Tesis doctoral inédita, Universitat de València.

—; Pérez, A.; Vidal, P.; Sanchís, A. (2014): Prácticas rituales ibéricas en la Cueva del Sapo (Chiva, Valencia): más allá del caliciforme. Zephyrus, LXXIV: 157-179.

—; Sanchis, A. (2015): La ofrenda de animales como práctica ritual en época ibérica: la Cueva del Sapo (Chiva, Valencia), Preses petites i grups humans en el passat (A. Sanchis, J. L. Pascual, eds.), II Jornades d'Arqueozoologia del Museu de Prehistòria de València, Valencia: 261-286.

Maggiani, A. (1999): Culti delle acque e culti in grotta in Etruria. Ocnus: Quaderni della Scuola de Specializzazione in Archeologia, 7: 187-203.

Martí Bonafé, Ma . A. (1990): Las Cuevas del Puntal del Horno Ciego. Villargordo del Cabriel, Valencia, Saguntum-PLAV, 23: 141-182.

Martínez García, J. M. (2011): Láminas argénteas con representaciones humanas y otros materiales de significación votiva en el territorio de Kelin y zonas adyacentes (La Plana de Utiel, Valencia). Intervencions sobre el patrimoni arqueologic. Excavació, restauració, difusió, posada en valor (L. Alapont, J, Martí, eds.), Valencia: 31-50.

- (2002): Texeda la Vieja (Garaballa). Arqueología y mitología de un espacio sagrado en la serranía de Cuenca. Utiel.

Martínez Perona, J. V. (1992): El santuario ibérico de la Cueva Merinel (Bugarra). En torno a la función del vaso caliciforme. Estudios de Arqueología ibérica y romana. Homenaje a Enrique Pla Ballester (J. Juan Cabanilles, coord.), Serie de Trabajos Varios del SIP, 89, Valencia: 261-282.

Martínez Valle, A. (1995): En torno a la localización de la ceca de Ikalesken. Actas IX Congreso Nacional de Numismática, Elche: 59-66.

-; Castellano, J. J. (1996): Conjunto de fusayolas ibérica de dos cuevas santuario de la comarca de Requena Utiel. Actas del XXIII Congreso Nacional de Arqueología, Vol. I: 525-536.

Mata, C. (1991): Los Villares (Caudete de las Fuentes): origen y evolución de la cultura ibérica. Serie de Trabajos Varios del SIP, 88, València.

-; Duarte, F.; Ferrer, M. A.; Garibo, J.; Valor, J. (2001): Kelin (Caudete de las Fuentes, Valencia) y su territorio. Los Íberos en la Comarca de Requena-Utiel (A. J. Lorrio, ed.), Serie Arqueológica, Alicante: 76-87.

—; Moreno, A.; Pérez Jordà, G.; Quixal, D.; Vives-Ferrándiz, J. (2009): Casas y cosas del campo: hábitat agrícola y estructura social en los territorios de Edeta y Kelin (siglos V-III A.N.E.). Actes de la IV Reunió d'Arqueologia de Calafell, Arqueomediterránea, 10, Barcelona: 143-152.

—. (coord.) (2014): Fauna Ibérica. De lo real a lo imaginario (II). Serie de Trabajos Varios del SIP, 117, Valencia.

Molina, G.; Pedraz, T. (2000): Nuevo aporte al Eneolítico valenciano: la Cueva de las Mulatillas (Villargordo del Cabriel, Valencia). Anales de Prehistoria y Arqueología, 16: 7-15.

- (2001): La posible cueva-santuario de El Molón (Camporrobles, Valencia). Los íberos en la Comarca de Requena-Utiel (Valencia) (A. J. Lorrio, ed.), Serie Arqueológica, Alicante: 171-182.

Moneo, T. (2003): Religio ibérica: santuarios, ritos y divinidades (siglos VII-I a.C.). Real Academia de la Historia, Madrid.

Moreno, A. (2011): Cuando el paisaje se convierte en territorio: aproximación al proceso de territorialización íbero en La Plana d'Utiel, València (ss. VI-II ane). BAR International Series, 2298, Oxford.

Moya, F. (1998): La Cueva Santa del Cabriel (Mira, Cuenca). Aproximación a la evolución histórico-religiosa del Santuario y de la imagen alli venerada. Ayuntamiento de Fuenterrobles, Utiel.

Ocharán, J. A. (2014): Proyecto Arqueológico del Santuario Rupestre Ibérico de la Nariz (Moratalla, Murcia). La fuerza de las pequeñas respuestas al gran problema o cómo investigar en época de crisis. Monográfico, 9, Junta de Extremadura: 741-154.

- (2015): Santuarios rupestres ibéricos de la Región de Murcia. Verdolay, 14: 103-142.

Olmos, R.; Tortosa, T. (2010): Aves, diosas y mujeres, La Dama de Baza: Un viaje femenino al más allá (T. Chapa, M. I. Izquierdo, coords.), Actas del Encuentro Internacional Museo Arqueológico Nacional, Madrid: 243-258.

Pérez Ballester, J. (1992): El Abrigo de Reiná (Álcala del Júcar). Ensayo sobre un nuevo modelo de lugar de culto en época ibérica. Estudios de arqueología ibérica y romana: homenaje a Enrique Pla Ballester (J. Juan Cabanilles, coord.), Serie de Trabajos Varios del SIP, 89, Valencia: 117-174.

Pericot, L. (1946): La Cueva de la Cocina (Dos Aguas). Archivo de Prehistoria Levantina, II: 398-71. 
Piqueras, J. (1997): La Meseta de Requena-Utiel. Centro de Estudios Requenenses, Requena.

Pla Ballester, E. (1946): Cova de les Meravelles. APL II: 191-202.

- (1966): Actividades del Servicio de Investigación Prehistórica (1961-1965). Archivo de Prehistoria Levantina, XI: 275-328.

Prados, L. (1994): Los santuarios ibéricos. Apuntes para el desarrollo de una arqueología de culto. Trabajos de Prehistoria, 51 (1): 129-140.

- (1996): Los ritos de paso y su reflejo en la toréutica ibérica. Coloquio internacional: Iconografía Ibérica, Iconografía Itálica, Madrid: 273-282.

- (2004): Un viaje seguro: Las representaciones de pies y aves en la iconografía de época ibérica. Cuadernos de Prehistoria y Arqueología de la Universidad Autónoma de Madrid, 30: 91-104.

Quixal, D. (2008): El valle del Magro entre los siglos VI-I a.C.: una aproximación a la movilidad en época ibéirca. Universitat de València, Trabajo de investigación inédito.

- (2012): El valle del Magro como vía de comunicación en época ibérica (siglos VI-I a.C.). Archivo de Prehistoria Levantina, XXIX: 187-208.

- (2013): Las comunicaciones entre los territorios ibéricos del interior valenciano: Kelin y La Carència entre los siglos VI-I a.C. L'oppidum de la Carència de Torís i el seu territorio (R. Albiach, coord.), Serie de Trabajos Varios del SIP, 116, Valencia: 293-301.

- (2015): La Meseta de Requena-Utiel (Valencia) entre los siglos II a.C. y II d.C. La Romanización del territorio ibérico de Kelin. Serie de Trabajos Varios del SIP, 118, Valencia.

-; Mata, C.; Albelda, V.; Pérez Reyes, A. (2010): Primera campaña de excavación en el asentamiento ibérico final de la Casa de la Cabeza (Requena, València). Saguntum-PLAV, 42: 115-117.

-; Moreno, A. (2011): Vadocañas y los vados sobre El Cabriel en época ibérica. El Lebrillo Cultural. Boletín de la Asociación Cultural de Amigos de Venta del Moro, 28: 15-20.

—; Moreno, A.; Mata, C. (2007): Campaña de prospección en el valle del río Magro / corredor de Hortunas (Requena-Yátova, València). Saguntum-PLAV, 39: 209-211.

—; Pérez Jordà, G.; Moreno, A.; Mata, C.; Carrión, Y. (2016): Bodegas, lagares y almazaras en el territorio de Kelin (siglos V-III a. C.): el caso de la Rambla de la Alcantarilla (Requena, Valencia). Archivo Español de Arqueología, 89: 25-43.

Ramos, R. (1997): La representación de grifos en la cerámica ibérica de la Alcudia. Su interpretación simbólica, Actas del XXIII Congreso Nacional de Arqueología, Vol 1: 313-318.

Rísquez, C.; Rueda, C. (eds.) (2013): Santuarios iberos: Territorio, ritualidad y memoria. Actas del Congreso Internacional "El Santuario de la Cueva de La Lobera de Castellar. 1912-2012”, Jaén.

Ros, A. (2003): L'ús de coves santuari al massís del Garraf durant el període ibèric. IV Trobada d'Estudiosos del Garraf, Diputació de Barcelona: 181-185.

Rueda, C. (2011): Territorio, culto e iconografia en los santuarios iberos del Alto Guadalquivir (ss. IV a.n.e.-I d.n.e.). CAAI Textos, Universidad de Jaén.

Ruiz Rodríguez, A.; Chicharro, J. L.; Molinos, M. (2000): Exposición El Santuario Ibérico de "El Pajarillo" (Huelma, Jaén). Junta de Andalucía, Jaén.

Sarrión, I. (1990): Estudio de la Fauna de la Cueva II. Las Cuevas del Puntal del Horno Ciego (Villagordo del Cabriel, Valencia). Saguntum-PLAV, 23: 180-182.

Serrano, D.; Fernández, J. (1992): Cuevas rituales ibéricas en la provincia de Valencia. Al-Gezira, 7: 11-35. Tarradell, M. (1973): Cuevas sagradas o cuevas santuario: un aspecto poco valorado en la religión ibérica. Memoria de 1973 del Instituto de Arqueología y Prehistoria (Universidad de Barcelona): 25-40.

Vega, J. de la (1987): Contribució catalana a l'inventari de les probables coves santuari ibèriques. Fonaments, 6: 171-192.

VVAA (1974): La labor del SIP y su museo en el pasado año 1972. Valencia.

VVAA (1975): La labor del SIP y su museo en el pasado año 1973. Valencia.

VVAA (1976): La labor del SIP y su museo en el pasado año 1974. Valencia. 